\title{
INCREMENTO DIAMÉTRICO E EM ÁREA BASAL NO PERÍODO 1979-2000 DE ESPÉCIES ARBÓREAS DE UMA FLORESTA OMBRÓFILA MISTA LOCALIZADA NO SUL DO PARANÁ
}

\author{
Luciano Budant Schaaf*, Afonso Figueiredo Filho**, Carlos Roberto Sanquetta***, Franklin Galvão*** \\ * Eng. Florestal, M.Sc. - schaaf@amazon.com.br \\ ** Eng. Florestal, Dr., Depto. de Engenharia Florestal. UNICENTRO - afig@floresta.ufpr.br \\ *** Eng. Florestal, Dr., Depto. de Ciências Florestais, UFPR - sanqueta@floresta.ufpr.br - fgalvao@floresta.ufpr.br \\ Recebido para publicação: 06/05/2005 - Aceito para publicação: 22/08/2005
}

\begin{abstract}
Resumo
Incremento diamétrico e em área basal no período 1979-2000 de espécies arbóreas de uma Floresta Ombrófila Mista localizada no sul do Paraná. Com o objetivo de estudar o incremento das espécies que ocorrem em uma Floresta Ombrófila Mista, localizada na Estação Experimental da UFPR (São João do Triunfo/PR), nove parcelas, totalizando nove hectares, avaliados inicialmente em 1979, foram recuperadas e medidas em 2000. Em 1979, todos os indivíduos arbóreos com DAP igual ou superior a $20 \mathrm{~cm}$ foram identificados, numerados e tiveram seus diâmetros medidos. Em 2000, usando os mesmos critérios de inclusão, os indivíduos que não haviam sido computados em 1979 foram considerados como ingressos e os não encontrados como mortos. Em 1979, nos nove hectares estudados, foram encontrados 2133 indivíduos e 51 espécies; em 2000, 2202 indivíduos e 55 espécies. A distribuição dos incrementos diamétricos da floresta é bimodal e em área basal individual é unimodal, entretanto, ambos apresentaram assimetria à direita (positiva). Os indivíduos arbóreos cresceram em 21 anos, em termos de mediana, $5,30 \mathrm{~cm}(0,25$ $\mathrm{cm} / \mathrm{ano})$ em diâmetro e $0,0288 \mathrm{~m}^{2}\left(0,0014 \mathrm{~m}^{2} / \mathrm{ano}\right)$ em área transversal. Nectandra megapotamica foi a espécie que apresentou os maiores incrementos, seguida de Cedrela fissilis. Por outro lado, Eugenia sp. e Allophylus edulis foram as espécies com os menores incrementos. Os incrementos variaram em função das classes de diâmetro, da vitalidade, posição sociológica e qualidade do fuste, sendo maiores para as classes de diâmetro intermediárias (40 a $80 \mathrm{~cm}$ ), classe de melhor vitalidade, estrato superior e classe de melhor qualidade de fuste. A floresta amadureceu no período estudado, pois teve um crescimento líquido em área basal de $45,3055 \mathrm{~m}^{2}\left(5,0339 \mathrm{~m}^{2} / \mathrm{ha}\right.$ ou $0,2397 \mathrm{~m}^{2} / \mathrm{ha} /$ ano $)$, mostrando que a floresta não estava completamente estocada em 1979.

Palavras-chave: Floresta com araucária; crescimento diamétrico; crescimento em área basal; distribuição dos incrementos.
\end{abstract}

\begin{abstract}
Diameter and basal area increment of arboreal species from an Ombrophyllous Mixed Forest located at the south of Parana state in the period from 1979-2000. This researd intend to study the diameter and basal area increment of the species from an Ombrophyllous Mixed Forest located in São João do Triunfo (Parana State - Brazil). Nine plots of 1 ha, first evaluated in 1979, were recovered and measured in 2000. In 1979, all trees with diameter $(d b h) \geq 20 \mathrm{~cm}$ were identified, numbered and had its $d b h$ measured. In 2000, based on the same criteria, trees which had not been counted in 1979 were considered as ingrowth, the missing ones were considered dead. In 1979, the sample (9 ha) had 2,133 trees of 51 species. In 2000, the number of trees increased to 2,202 and the species to 55. The distribution of the diameter increment is bimodal and the individual basal area is unimodal of all species. In both cases, the distribution is skewed to the right. During the period between 1979-2000, regarding to the median of the arboreal trees, they increased $5,3 \mathrm{~cm}(0.25 \mathrm{~cm} /$ year $)$ of the $d b h$ and $0.02882 \mathrm{~m}^{2}\left(0.0014 \mathrm{~m}^{2} /\right.$ year of the basal area. The Nectandra megapotamica and Cedrela fissilis species showed the highest increments. On the other hand, Eugenia sp. and Allophylus edulis species showed the lowest increments. The trees increment changed due to the diameter size, vitality, sociological position and stem quality classes, being higher in classes which present averaged $d b h$ (40 to $80 \mathrm{~cm}$ ), better vitality, superior stratum and better quality stem. The forest aged during the studied period, for it presented a net growth in basal area of $45.3055 \mathrm{~m}^{2}\left(5.0339 \mathrm{~m}^{2} / \mathrm{ha}\right.$ or $0.2397 \mathrm{~m}^{2} / \mathrm{ha} /$ year $)$. This fact confirm that the forest still had available space to allow growth, therefore it was not fullstocked in 1979.
\end{abstract}

Keywords: Araucaria forest; diameter growth; basal area growth; increment distribution. 


\section{INTRODUÇÃO}

Até o início deste século, grande parte da cobertura florestal original do sul do Brasil era formada por florestas dominadas por Araucaria angustifolia (Bertol.) Kuntze (Maack, 1931; Heinsdijk, 1959; Dillewijn, 1966; ESCOLA DE FLORESTAS, 1967). Contudo, o processo de colonização, exploração madeireira e expansão das áreas agrícolas conduziu à progressiva redução dessas florestas (Péllico-Netto, 1971; Eduardo, 1974; FUPEF, 1978).

A realização de estudos detalhados sobre a dinâmica de florestas é fundamental para assegurar a sua conservação e eventual manejo, mas ao mesmo tempo é uma tarefa difícil, que envolve dedicação e observações de longo prazo, tendo em vista a complexidade, heterogeneidade e lentidão dos processos dinâmicos desses ecossistemas.

A metodologia conhecida mais indicada para tal finalidade é a instalação e medição de parcelas permanentes. Goldsmith e Harrison (1976) afirmam que mudanças na vegetação em longos períodos são melhor estudadas através de parcelas permanentes ou de transectos permanentes. Para Alder e Synnott (1992), uma amostragem da dinâmica, utilizando-se parcelas permanentes, concentra-se inicialmente na medição de taxas de mudança, incluindo o incremento diamétrico e a taxa de mortalidade e de ingresso.

$\mathrm{O}$ crescimento das árvores consiste da elongação e aumento da espessura das raízes, troncos e galhos, provocando mudanças em termos de tamanho e forma. O crescimento linear (elongação) de todas as partes da árvore resulta da atividade do meristema primário. Já o crescimento em diâmetro (aumento da espessura), da atividade do meristema secundário ou câmbio (Husch et al., 1982).

De acordo com Vanclay (1994) e Prodan et al. (1997), entende-se por crescimento o aumento de dimensões de um ou mais indivíduos em uma floresta em um determinado período de tempo. Tais dimensões podem ser o diâmetro, a altura, o volume, a biomassa, a área basal etc. Já a produção refere-se às dimensões finais ao término de determinado período. Portanto, a produção é o crescimento acumulado, enquanto o crescimento é a taxa de produção. Tal conceito pode ser expresso matematicamente, sendo que, se a produção for considerada $y$, o crescimento é $\partial \mathrm{y} / \partial \mathrm{t}$, ou seja, a primeira derivada da produção (y) em relação ao tempo $(t)$.

De acordo com Alder e Synnott (1992), em florestas, ao contrário dos plantios florestais, o crescimento individual e o crescimento da floresta não podem ser igualados. Nos plantios monoespecíficos, com ingresso e mortalidade desprezíveis, é correto assumir que o crescimento do povoamento é igual à soma dos crescimentos das árvores individuais. No entanto, o crescimento das florestas durante um período de tempo possui três componentes: a) crescimento ou incremento da árvore individual; b) mortalidade; c) ingresso, ou o aparecimento de novas árvores, vindas da regeneração, nas classes de diâmetro inferiores.

Esse conceito pode ser expresso matematicamente através expressão $\mathrm{I}=\mathrm{I}_{\mathrm{S}}-\mathrm{M}+\mathrm{R}$, onde: $\mathrm{I}=$ incremento líquido ou crescimento da floresta; $\mathrm{I}_{\mathrm{S}}=$ soma dos incrementos das árvores que sobreviveram no período estudado; $\mathrm{M}=$ volume das árvores que morreram durante o período; $\mathrm{R}=$ volume do ingresso (regeneração) medido ao final do período.

Os mesmos autores concluem que, para parcelas permanentes instaladas em florestas, medições acuradas do ingresso e da mortalidade são tão importantes quanto medições do incremento individual das árvores.

Segundo Husch et al. (1982), o crescimento das árvores é influenciado pelas características da espécie, interagindo com o ambiente. Para Prodan et al. (1997), as influências ambientais incluem fatores climáticos (temperatura, vento, precipitação e insolação), fatores pedológicos (características físicas e químicas, umidade e microrganismos), características topográficas (inclinação, elevação e aspecto) e competição (influência de outras árvores, sub-bosque e animais), sendo que a soma desses fatores exprime o conceito de qualidade de hábitat ou sítio.

Oliver e Larson (1996) apresentam o conceito de espaço de crescimento, que expressa a capacidade de as plantas crescerem até que um fator necessário ao crescimento torne-se limitante. A quantidade de espaço de crescimento varia no espaço e no tempo. A luz, a água, os nutrientes, a temperatura, o oxigênio e o gás carbônico são os fatores que limitam o espaço de crescimento. 
Este estudo visou analisar o incremento em diâmetro e área basal usando parcelas permanentes instaladas em 1979 e remedidas no ano 2000 (21 anos) em um remanescente de Floresta Ombrófila Mista localizado no município de São João do Triunfo, estado do Paraná.

\section{MATERIAL E MÉTODOS}

\section{Características da área}

Este estudo foi feito na Estação Experimental da Universidade Federal do Paraná, localizada no município de São João do Triunfo (cerca de $125 \mathrm{~km}$ de Curitiba), estado do Paraná - Brasil, no Segundo Planalto. A altitude do local é de $780 \mathrm{~m}$ s.n.m. e possui coordenadas geográficas de $25^{\circ} 34^{\prime} 18^{\prime \prime} \mathrm{S}$ e $50^{\circ} 05^{\prime} 56^{\prime \prime} \mathrm{W}$. A floresta ali existente tem uma área total de 32,36 ha, dividida em 32 parcelas, com área aproximada de 1 ha $(100 \times 100 \mathrm{~m})$ cada.

De acordo com a classificação climática de Köppen, a região apresenta clima do tipo Cfb (Longhi, 1980; Rodríguez Tello, 1980; Pizatto, 1999; Durigan, 1999), caracterizado por ser mesotérmico, sempre úmido e com verões brandos. O clima é típico do planalto meridional brasileiro, com temperaturas médias anuais entre $14{ }^{\circ} \mathrm{C}$ e $19{ }^{\circ} \mathrm{C}$ e precipitação anual entre 1.250 e $2.000 \mathrm{~mm}$. Dados climáticos médios obtidos das Estações Meteorológicas do IAPAR da Lapa, Fernandes Pinheiro e Ponta Grossa, próximas à área de estudo (adaptado de Durigan, 1999), indicam uma temperatura média anual de $17,4^{\circ} \mathrm{C}$, umidade relativa média anual de $80,1 \%$ e precipitação média anual de $1.615 \mathrm{~mm}$, sendo janeiro o mês mais chuvoso e agosto o mais seco.

Segundo Longhi (1980), baseado num levantamento realizado na área, o solo predominante é do tipo Argissolo Vermelho-Amarelo distrófico, sendo encontrado também, em pequena proporção, Cambissolo distrófico álico.

Durigan (1999), através de prospecções realizadas também nessa Estação Experimental, identificou a ocorrência de Latossolo Vermelho-Escuro e Latossolo Vermelho-Amarelo, além de Cambissolos (Cambissolo gleico, nas cotas mais baixas) e Neossolos litólicos.

Baseando-se na classificação proposta pelo IBGE (1992), a tipologia vegetal dominante na área é a Floresta Ombrófila Mista Montana, que, apesar de não ter sofrido corte raso, é bastante alterada, enquadrando-se como uma vegetação primária muito alterada, ou uma formação secundária avançada, visto que possui algumas características estruturais de formações primárias e intervenções antrópicas características de formações secundárias.

A área foi adquirida em 1969 de colonos da região, tendo sofrido corte seletivo em algumas parcelas (Longhi, 1980). Segundo declarações do Sr. Deonízio Kieras, funcionário responsável pela Estação Experimental desde 1972, a floresta, apesar de não ter sofrido corte raso, foi alterada pelas seguintes intervenções: a) exploração seletiva de araucárias - retirada de indivíduos de grandes dimensões (antes de 1972); b) exploração de erva-mate (antes de 1972); c) corte dos indivíduos mais finos, implementado em algumas parcelas; d) incêndio que afetou as parcelas próximas à estrada (em 1982); e) exploração e poda da erva-mate (em 1983).

\section{Obtenção dos dados}

Este estudo fundamentou-se no levantamento realizado por Solon Jonas Longhi e Julio César Rodríguez Tello, em 1979, no qual foram coletados dados referentes a todos os indivíduos arbóreos presentes em nove parcelas de 1 ha, cujo DAP (diâmetro a 1,3 m) era igual ou superior a $20 \mathrm{~cm}$. Foram selecionadas 9 parcelas $(1,6,7,10,17,18,21,22$ e 30), totalizando 9 hectares, com base na abundância de Araucaria angustifolia na fase adulta.

Foram registradas, em 1979, para cada indivíduo, as seguintes informações: nome vulgar, DAP e altura total e comercial (Longhi, 1980). Os diâmetros foram obtidos utilizando-se uma suta, com precisão de $0,5 \mathrm{~cm}$.

Em 2000, usando o mesmo critério de inclusão, todos os indivíduos ocorrentes nas nove parcelas tiveram seus diâmetros medidos. Os diâmetros, nessa ocasião, foram obtidos com fita métrica ou trena (indivíduos maiores), com precisão de $0,5 \mathrm{~cm}$. Os indivíduos foram etiquetados com fita 'rotex' e pregos.

West (1980), estudando florestas de Eucalyptus na Tasmânia, concluiu que a priori não existe motivo para se preferir estudar o crescimento em termos de diâmetro ou de área basal. Neste estudo, foram efetuadas as duas análises, considerando tanto o incremento em diâmetro como em área basal. 


\section{Incremento diamétrico}

$\mathrm{O}$ incremento diamétrico foi avaliado com base no crescimento em diâmetro dos indivíduos medidos nas duas ocasiões, 1979 e 2000, ou seja, aqueles que permaneceram vivos durante o período estudado.

$\mathrm{O}$ incremento periódico em diâmetro foi calculado usando-se a fórmula $\mathrm{IP}_{\mathrm{d}}=\mathrm{d}_{2000}-\mathrm{d}_{1979}$, onde: $d_{2000}=$ DAP em $2000(\mathrm{~cm}) ; d_{1979}=$ DAP em $1979(\mathrm{~cm})$.

$\mathrm{O}$ incremento periódico anual em diâmetro foi calculado através da fórmula $\mathrm{IPA}_{\mathrm{d}}=\mathrm{IP}_{\mathrm{d}} / \mathrm{P}$, onde: $P$ = intervalo de medição, no caso, 21 anos.

Todas as análises relativas aos incrementos foram baseadas no incremento periódico, sendo que o incremento periódico anual em diâmetro foi calculado apenas para as espécies. O motivo de se tomar tal atitude é que, ao se dividir o incremento periódico pelo intervalo de medição, estar-se-á assumindo que as árvores cresceram de forma linear no período, o que contraria o formato sigmóide apresentado pela curva de crescimento dos seres vivos.

\section{Incremento em área transversal e área basal/ha}

$\mathrm{O}$ incremento em área transversal foi calculado para cada árvore, assim como a área basal para cada talhão e para a floresta inteira $(9 \mathrm{ha})$. $\mathrm{O}$ incremento periódico em área transversal por árvore foi calculado através da fórmula $\mathrm{IP}_{\mathrm{g}}=\mathrm{g}_{2000}-\mathrm{g}_{1979}$, onde: $g_{2000}=$ área transversal em $2000\left(\mathrm{~m}^{2}\right)$; $g_{1979}=$ área transversal em $1979\left(\mathrm{~m}^{2}\right)$.

Como não foram feitas considerações a respeito do volume das árvores, visto que não foram medidas alturas na segunda ocasião (2000) e as relações hipsométricas ajustadas mostraram-se insatisfatórias, considerou-se a área basal como a variável disponível que mais se aproxima da biomassa, tanto das árvores como das parcelas e da floresta. Assim, o incremento em área basal, como expressão do balanço da biomassa da floresta e das parcelas, foi calculado baseando-se na metodologia proposta por Alder e Synnott (1992) para o cálculo do incremento volumétrico do povoamento. Essa metodologia, como exposta anteriormente, considera o incremento líquido da floresta, ou seja, além do incremento em área transversal das árvores que permaneceram vivas, considera também a área transversal das árvores mortas e dos ingressos, utilizando-se da equação: $\mathrm{IG}=\mathrm{G}_{\mathrm{v}}-\mathrm{G}_{\mathrm{m}}+\mathrm{G}_{\text {in }}$, onde: $G_{v}=$ incremento em área basal no período 1979 a 2000, das árvores que permaneceram vivas, ou seja, $\sum \mathrm{IP}_{\mathrm{g}} ; G_{m}=$ área basal das árvores mortas; $G_{i}=$ área basal das árvores que ingressaram.

\section{Análises dos incrementos agrupando-se os dados em classes}

$\mathrm{O}$ crescimento/incremento, em diâmetro e área transversal, foi também analisado em classes de diâmetro de $10 \mathrm{~cm}$ e em função das variáveis qualitativas: vitalidade, posição sociológica e qualidade do fuste.

A inclusão de árvores em diferentes classes de vitalidade e qualidade do fuste foram feitas por observação visual, procurando-se analisar o estado de desenvolvimento de cada parâmetro. As árvores foram classificadas em três classes (boa, média e ruim), tanto para a qualidade do fuste como para a vitalidade (Longhi, 1980). Os padrões adotados para qualidade do fuste foram os seguintes:

Classe 1 - fuste reto, bem configurado, sem defeitos aparentes, permitindo obter toras de alta qualidade;

Classe 2 - fuste com tortuosidades, pequenos nós ou secção transversal elíptica e em geral com aproveitamento restrito;

Classe 3 - fuste oco e deformado, ou atacado por insetos e fungos causadores do apodrecimento, em geral com aproveitamento mínimo ou nulo.

Para a classificação da vitalidade, os padrões adotados foram os seguintes:

Classe 1 - árvore sadia, com copa bem desenvolvida, apresentando um volume proporcional às dimensões da árvore;

Classe 2 - árvore apresentando copa medianamente desenvolvida, com sintomas doentios;

Classe 3 - árvore atacada por insetos e fungos e apresentando copas defeituosas.

A classificação das árvores em diferentes estratos foi feita com base na metodologia utilizada por Martins (1991), considerando-se para a delimitação das posições sociológicas das árvores três estratos: 
inferior, médio e superior. Maiores detalhes sobre a metodologia empregada neste trabalho podem ser consultados em Schaaf (2001).

\section{RESULTADOS E DISCUSSÕES}

\section{Problemas relacionados ao estudo do crescimento}

Das 2133 árvores medidas em 1979, 1620 permaneceram vivas em 2000. Baseando-se nessas árvores, foi realizada a análise dos incrementos, tanto em termos diamétricos como em relação à área transversal e área basal por parcela e para a floresta (9 ha). Ao se computar o crescimento dessas árvores, surgiram alguns problemas, principalmente ligados à existência de incrementos negativos, ou seja, árvores "diminuindo" de tamanho: das 1620 árvores vivas, 61 apresentaram incrementos negativos $(3,77 \%)$. Esse é um fato relativamente comum em florestas onde os incrementos são diminutos, principalmente quando comparados aos de plantios comerciais.

$\mathrm{Na}$ maioria das vezes, como os intervalos de medição são curtos, os incrementos tornam-se menores que os erros de medição. Por esse motivo, esperava-se que neste trabalho, cujo intervalo de medição foi de 21 anos, tal problema desaparecesse. Uma das causas de sua persistência foi o fato de que, em 1979, os diâmetros foram tomados com a utilização de uma suta, enquanto que em 2000 utilizou-se uma fita. A posição de tomada dos diâmetros não foi marcada em 1979, o que pode ter gerado erros em função da diferença de altura em que os diâmetros em 1979 e em 2000 foram tomados. Por exemplo, se em 1979 o diâmetro foi medido numa posição inferior à medição realizada em 2000 e o crescimento apresentado pela árvore for pequeno, o valor do diâmetro em 1979 provavelmente será superior ao valor encontrado em 2000.

Assim sendo, surgiu a dúvida em se considerar, ou não, os valores negativos nos cálculos dos incrementos. Alguns autores optam por considerá-los (Pizatto, 1999), outros não. Durigan (1999) fez análises distintas, uma considerando os incrementos negativos e outra desconsiderando-os. A opção de considerá-los torna-se mais realista na medida em que, ao ignorá-los, estar-se-á superestimando o valor dos incrementos, pois, da mesma maneira que erros de medição produzem incrementos negativos, podem também produzir incrementos superestimados. Além disso, independentemente dos erros de medição, muitas árvores realmente apresentam uma diminuição no diâmetro, causada tanto pela queda da casca, como pelo apodrecimento e deterioração de parte do tronco.

Por esse motivo, decidiu-se, neste estudo, considerar todos os valores dos diâmetros obtidos em 2000, independentemente de gerarem incrementos negativos e de sua intensidade. Essa decisão foi fundamentada em dois motivos, além daqueles discutidos anteriormente:

a) ao se tentar eliminar os possíveis erros de medição ocorridos em 2000, estar-se-ia ignorando os possíveis erros cometidos em 1979, ou seja, um diâmetro obtido em 2000 foi menor do que aquele obtido em 1979, ou por um erro de medição ocorrido em 1979, ou por erro de medição ocorrido em 2000, sendo de difícil determinação em que ano o erro ocorreu;

b) ao se procurar eliminar os valores muito discrepantes pode-se cometer um novo erro; como exemplo, tem-se um indivíduo que apresentou decréscimo de $5,3 \mathrm{~cm}$ em seu diâmetro entre 1979 e 2000 devido a parte de seu tronco encontrar-se apodrecida, ou seja, esse indivíduo realmente diminuiu, sendo que se o valor de seu incremento for desconsiderado estar-se-á mascarando a realidade.

Essa decisão pode ser melhor visualizada na Figura 1, onde está apresentada a relação entre os diâmetros medidos nos anos de 1979 e de 2000.

A linha inferior representa o incremento diamétrico nulo, sendo que os pontos que aparecem abaixo dela representam as árvores com incrementos negativos. A linha intermediária representa o valor do incremento diamétrico médio e a linha superior o valor correspondente à média mais um desvio padrão.

Verifica-se, através da Figura 1, que é muito difícil determinar quais pontos localizados abaixo da reta inferior e muito acima da reta superior devem ser desconsiderados por serem frutos de erros de medição. Ao adotar-se que determinado ponto é discrepante e que deve ser retirado da análise, estar-se-á assumindo que uma árvore de certa espécie não pode apresentar determinado crescimento, o que constituiria um comportamento um tanto subjetivo. 


\section{Crescimento diamétrico e em área transversal}

Os indivíduos arbóreos da floresta ( $9 \mathrm{ha})$ apresentaram um incremento médio em diâmetro de $5,75 \mathrm{~cm}$ no período de 21 anos $(0,27 \mathrm{~cm} / \mathrm{ano})$, com mediana igual a $5,30 \mathrm{~cm}(0,25 \mathrm{~cm} /$ ano $)$ e coeficiente de variação de $71,33 \%$. O incremento mínimo observado foi de $-5,30 \mathrm{~cm}$ e máximo de $23,90 \mathrm{~cm}$ para $\mathrm{o}$ período.

Gomide (1997), estudando uma Floresta Ombrófila Densa primária no Amapá, encontrou um incremento periódico anual igual a $0,14 \mathrm{~cm} /$ ano, e para uma floresta secundária o referido autor encontrou o valor médio de 0,60 cm/ano. Gauto (1997) encontrou incrementos periódicos anuais de 0,58 cm/ano para uma Floresta Estacional Semidecidual em Missiones (Argentina). Durigan (1999) encontrou um incremento médio anual de $0,34 \mathrm{~cm} /$ ano para a mesma floresta objeto deste estudo. Já Pizatto (1999) encontrou um valor de incremento periódico anual de $0,18 \mathrm{~cm} / \mathrm{ano}$.

Na Figura 2 está apresentada a distribuição dos incrementos periódicos em classes de freqüência.

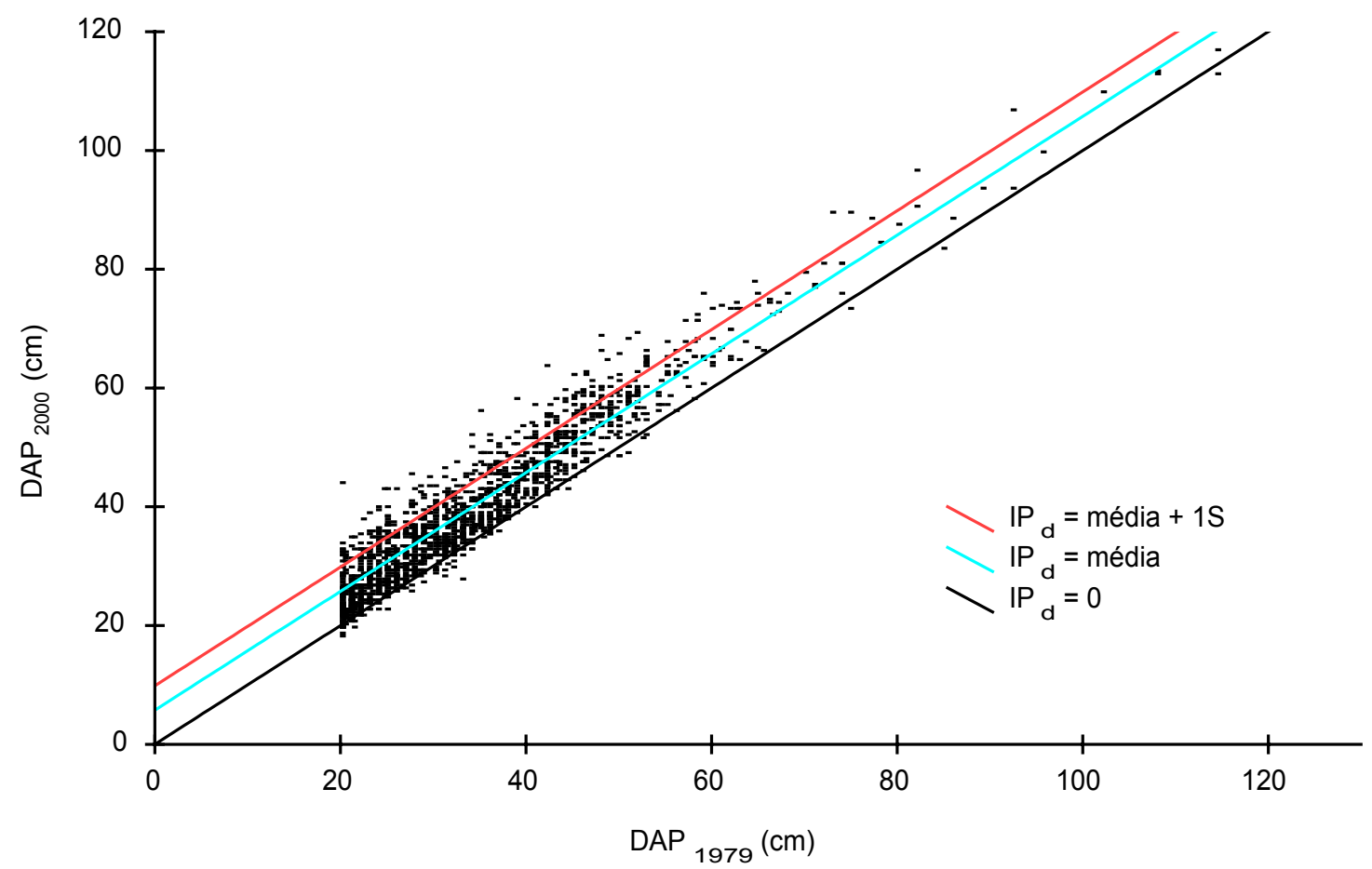

Figura 1. Relação entre o DAP medido em 1979 e o DAP medido em 2000 para as 1620 árvores que permaneceram vivas no período.

Figure 1. Relation between the measured dbh at 1979 and the mesured dbh at 2000 for 1620 remained trees in the period.

A análise da Figura 2 indica que os incrementos periódicos em diâmetro descrevem uma distribuição assimétrica positiva (o valor da média $-5,75 \mathrm{~cm}$ - é maior que o da mediana $-5,30 \mathrm{~cm}$ ), o que confirma, em parte, as observações de Kohyama e Hara (1989). Os autores estudaram florestas no Japão e na Indonésia e chegaram à conclusão de que, independente do tipo florestal e da classe de tamanho (classe de diâmetro), as distribuições das taxas de crescimento mostraram padrões unimodais com assimetria positiva. Essa assimetria positiva observada na distribuição dos incrementos é justificada pelos referidos autores como sendo produto da distribuição horizontal da luz, ou seja, como a distribuição horizontal da intensidade de luz entre árvores do mesmo tamanho tende para uma distribuição assimétrica positiva (com a densidade da folhagem tendo uma distribuição normal), os incrementos também tendem a seguir tal distribuição, visto que quanto maior a quantidade de luz disponível, maior o incremento. 
Outra conseqüência provocada pela assimetria verificada na distribuição dos incrementos é que, como medida de tendência central, a mediana deve ser preferida nos estudos de crescimento em detrimento da média aritmética, pois seu valor é menos influenciado pelos valores extremos.

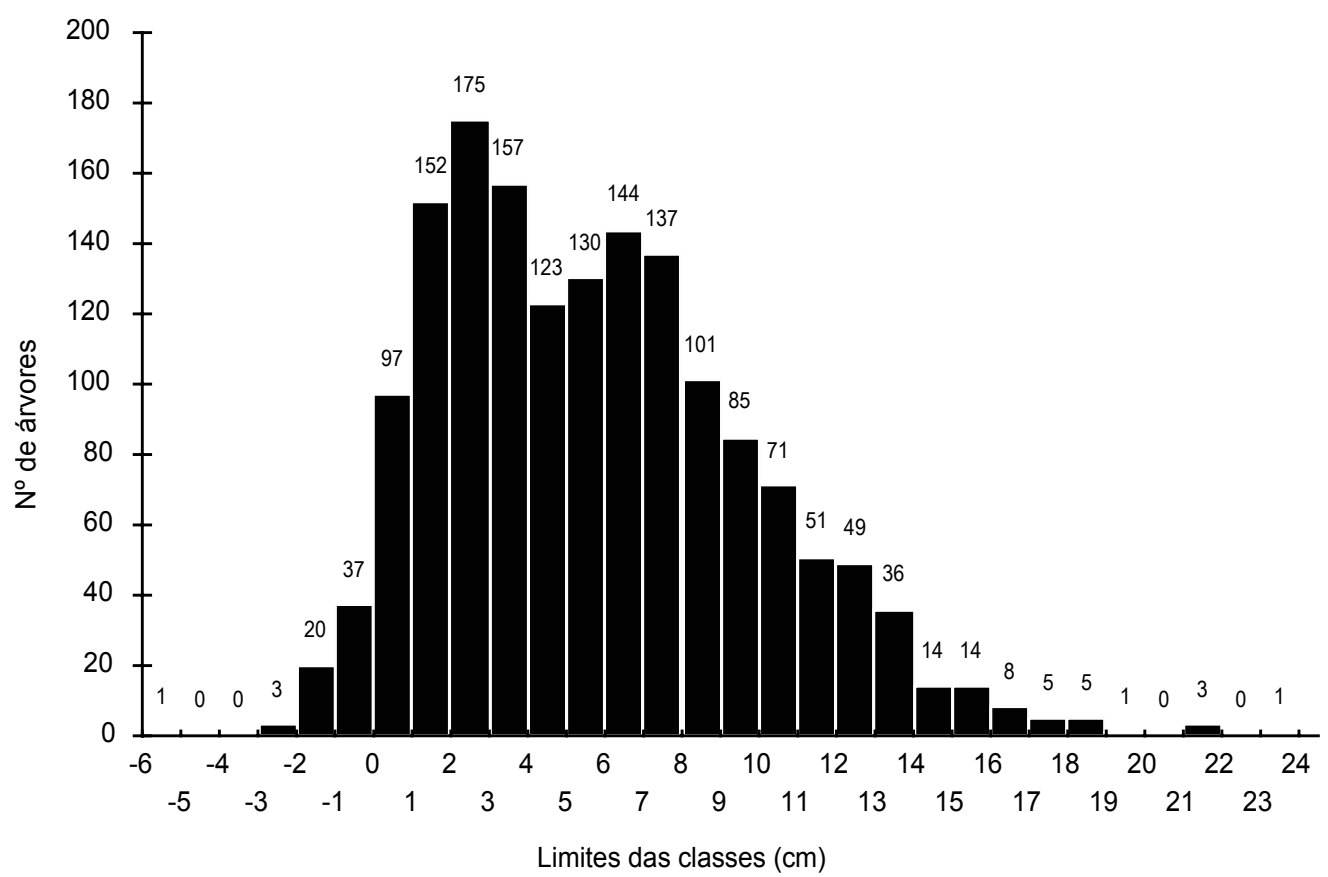

Figura 2. Distribuição de freqüência (9 ha) dos incrementos periódicos em diâmetro (1979-2000).

Figure 2. Frequency distribution (9 ha) of diameter periodic increments (1979-2000).

Apesar de neste trabalho ter sido constatada a assimetria positiva, a distribuição dos incrementos mostrou uma ligeira tendência bimodal, ao contrário do padrão verificado por Kohyama e Hara (1989). Durigan (1999), estudando 4 parcelas da mesma floresta objeto desse estudo, em um período de um ano, também encontrou uma distribuição de incrementos diamétricos bimodal para a floresta inteira. Contudo, algumas parcelas apresentaram distribuição unimodal. Pizatto (1999), estudando 3,5 hectares da mesma floresta, em período de três anos, encontrou uma distribuição de incrementos na forma de J-invertido. Esse resultado também foi verificado por Gauto (1997), que estudou uma Floresta Estacional Semidecidual, na Argentina, em um período de 2 anos.

Em termos de área transversal, a floresta apresentou um incremento médio de $0,03646 \mathrm{~m}^{2}$ em 21 anos $\left(0,001736 \mathrm{~m}^{2} / \mathrm{ano}\right)$, com mediana de $0,02882 \mathrm{~m}^{2}\left(0,001372 \mathrm{~m}^{2} / \mathrm{ano}\right)$ e com coeficiente de variação igual a $89,76 \%$. O menor incremento observado no período foi $-0,02680 \mathrm{~m}^{2}$ e o maior, $0,22049 \mathrm{~m}^{2}$.

Como pode ser observado na Figura 3, a distribuição dos incrementos em área transversal, apesar de também mostrar assimetria positiva, configurou-se como unimodal. Essa diferença observada nas duas distribuições deve-se ao fato de o incremento em área transversal ser influenciado pelo diâmetro inicial da árvore, ou seja, para um incremento diamétrico igual, quanto maior o diâmetro inicial da árvore maior será o incremento em área transversal. Esse fato demonstra que a maioria das árvores que apresentou incremento periódico entre $6 \mathrm{e}$ $8 \mathrm{~cm}$, configurando o segundo pico na distribuição dos incrementos diamétricos, possuía diâmetros pequenos.

Outra constatação interessante é que há uma concentração maior de indivíduos nas classes de incremento inferiores quando considera-se a área transversal em comparação ao diâmetro. Além disso, a variabilidade dos incrementos em área transversal (89,76\%) é maior do que em relação aos incrementos diamétricos $(71,33 \%)$.

Pelos valores das médias e das medianas dos incrementos diamétricos mostrados na Tabela 1, verifica-se que todas as classes de diâmetro apresentam assimetria à direita (média $>$ mediana), com exceção das classes 50,0 a $60,0 \mathrm{~cm}$ e 60,0 a 70,0 cm, que apresentaram assimetria à esquerda (média < mediana). Isso demonstra que o comportamento dos incrementos diamétricos é diferenciado em relação às classes de tamanho. 


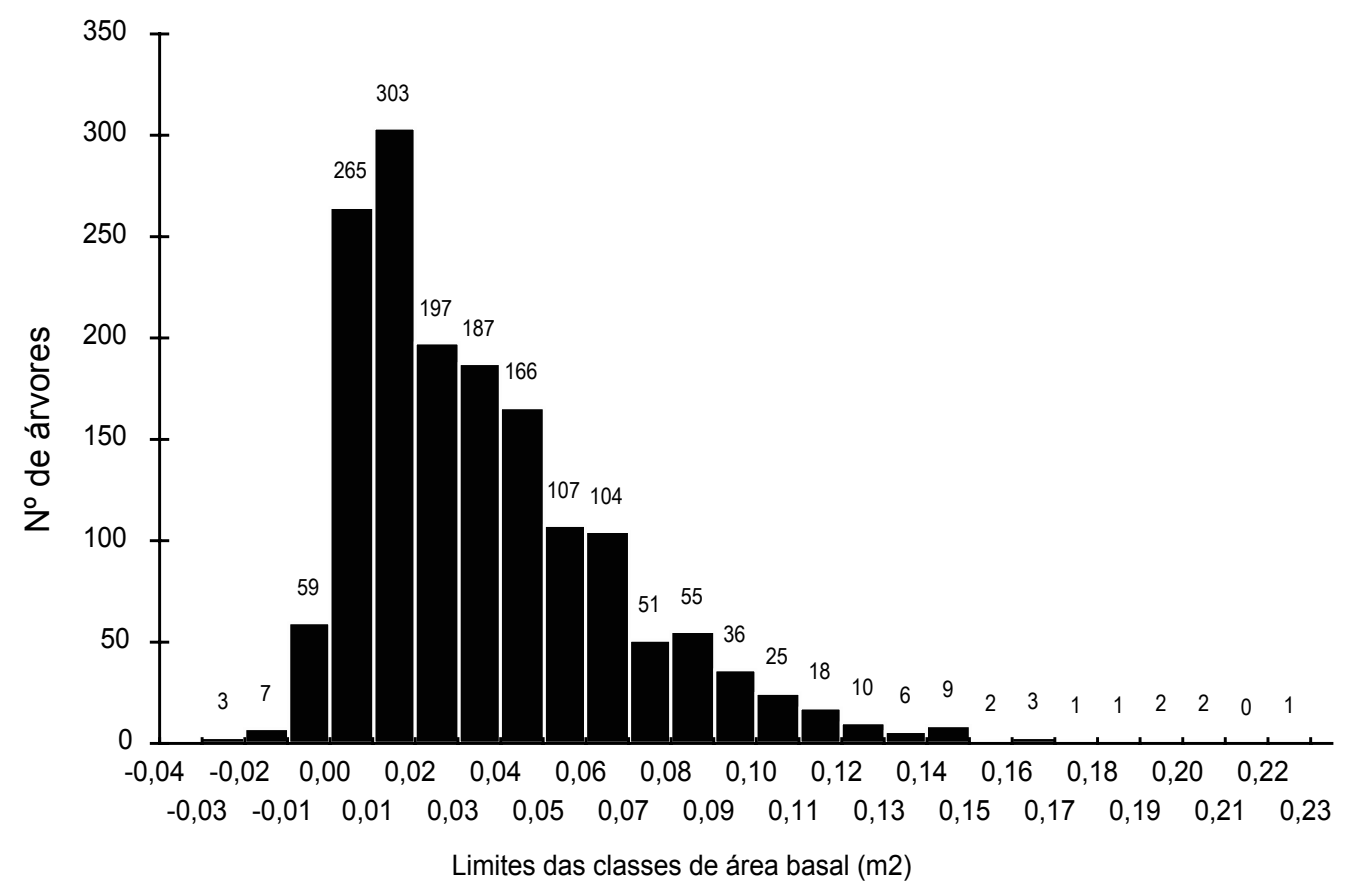

Figura 3. Distribuição de freqüência (9 ha) dos incrementos periódicos em área transversal (1979-2000). Figure 3. Frequency distribution (9 ha) of periodic increments in individual basal area (1979-2000).

Os maiores incrementos diamétricos periódicos foram verificados nas classes diamétricas intermediárias, na classe de 50,0 a $60,0 \mathrm{~cm}$, com mediana igual a 7,20 cm, e na classe 60,0 a $70,0 \mathrm{~cm}$, com mediana igual a $7,90 \mathrm{~cm}$.

Pulz (1998), estudando uma Floresta Estacional Semidecidual em Minas Gerais, entre 1987 e 1992, também verificou um maior incremento nas classes diamétricas próximas a $60 \mathrm{~cm}$. Gomide (1997) verificou comportamento semelhante em uma Floresta Ombrófila Densa primária no Amapá, sendo que os maiores incrementos foram verificados nas classes diamétrica superiores (próximas a $60 \mathrm{~cm}$ ). Pizatto (1999), estudando a mesma floresta da presente pesquisa entre 1995 e 1998, observou taxas de incremento maiores em classes diamétricas superiores (acima de $45 \mathrm{~cm}$ ).

Tabela 1. Incremento diamétrico por classe diamétrica para o período 1979-2000.

Table 1. Diameter increment per diameter classes in 1979-2000 period.

\begin{tabular}{|c|c|c|c|c|c|c|c|}
\hline $\begin{array}{c}\text { Classe de DAP } \\
(\mathrm{cm})\end{array}$ & $\begin{array}{c}\mathrm{N}^{\mathbf{0}} \text { de } \\
\text { Árvores } \\
\text { (9 ha) }\end{array}$ & $\begin{array}{l}\text { Média } \\
\text { (cm) }\end{array}$ & $\begin{array}{c}\text { Mediana } \\
(\mathrm{cm})\end{array}$ & $\begin{array}{l}\text { Mínimo } \\
\text { (cm) }\end{array}$ & $\begin{array}{l}\text { Máximo } \\
\text { (cm) }\end{array}$ & $\begin{array}{c}\text { Desvio } \\
\text { Padrão } \\
(\mathrm{cm})\end{array}$ & $\begin{array}{l}\text { C.V. } \\
(\%)\end{array}$ \\
\hline $20,0-30,0$ & 685 & 5,17 & 4,40 & $-2,1$ & 23,9 & 3,96 & 76,57 \\
\hline $30,0-40,0$ & 472 & 5,22 & 4,85 & $-5,3$ & 21,3 & 3,90 & 74,66 \\
\hline $40,0-50,0$ & 301 & 7,16 & 7,00 & $-1,5$ & 21,7 & 4,15 & 57,87 \\
\hline $50,0-60,0$ & 106 & 7,06 & 7,20 & $-1,8$ & 17,4 & 4,22 & 59,75 \\
\hline $60,0-70,0$ & 30 & 7,51 & 7,90 & 0,7 & 13,5 & 3,72 & 49,56 \\
\hline $70,0-80,0$ & 12 & 7,87 & 6,90 & $-1,8$ & 16,4 & 5,03 & 63,90 \\
\hline $80,0-90,0$ & 6 & 6,22 & 6,20 & $-1,4$ & 14,8 & 5,53 & 88,96 \\
\hline $90,0-100,0$ & 3 & 6,53 & 4,40 & 1,1 & 14,1 & 6,76 & 103,43 \\
\hline $100,0-110,0$ & 3 & 6,13 & 5,60 & 5,0 & 7,8 & 1,47 & 24,04 \\
\hline $110,0-120,0$ & 2 & 0,55 & 0,55 & $-1,5$ & 2,6 & 2,90 & 527,12 \\
\hline Total & 1620 & & & & & & \\
\hline
\end{tabular}


Como a análise dos resultados das classes de diâmetro superiores a $80 \mathrm{~cm}$ é pouco significativa à medida que a freqüência de indivíduos nessas classes é baixa, optou-se por desconsiderá-los. Assim, as classes diamétricas inferiores, diâmetros menores que $40 \mathrm{~cm}$, foram as que apresentaram os menores incrementos diamétricos.

Desse modo, o pressuposto de que as classes diamétricas inferiores concentram as árvores mais jovens e, portanto, deveriam apresentar incrementos maiores nem sempre é verdadeiro. Muitos indivíduos finos dispensam seus recursos mais na tentativa de se manterem na comunidade do que na produção de material lenhoso, podendo permanecer nessa condição por anos. Assim, existem muitas árvores finas que são "velhas". Por outro lado, em clareiras abertas pela queda de árvores, as árvores finas (pioneiras e/ou regeneração) são geralmente jovens, podendo desenvolver todo seu potencial de crescimento por suas copas estarem livres da interferência dos indivíduos dominantes. Isso é confirmado pela análise dos incrementos máximos, que são maiores nas classes inferiores.

Esse grande número de situações, às quais os indivíduos menores estão sujeitos, produziu uma grande variabilidade nos valores de seus incrementos. Desconsiderando-se as classes de diâmetro acima de $80 \mathrm{~cm}$, a classe diamétrica inferior é a que apresentou a maior variabilidade nos valores de seus incrementos $(76,57 \%)$.

Já as árvores mais grossas, que estão estabelecidas há mais tempo, gozando de uma posição privilegiada dentro do dossel, que lhes garante um aporte maior e mais constante de energia solar, apresentaram incrementos diamétricos maiores e com menor variabilidade.

Em termos dos incrementos em área transversal, apresentados na Tabela 2, verifica-se que a amplitude de variação entre as classes de diâmetro foi bem maior do que em relação aos incrementos diamétricos. A maior mediana do incremento em área transversal foi $0,08453 \mathrm{~m}^{2}$ (desconsiderando-se as classes de diâmetro acima de $80 \mathrm{~cm}$ ) e a menor foi $0,01805 \mathrm{~m}^{2}$, ou seja, quase quatro vezes menor que a maior mediana. Já em termos diamétricos, a razão entre a menor e a maior mediana foi menos de duas vezes $(4,40 \mathrm{~cm}$ para $7,90 \mathrm{~cm})$. Esse fato justifica-se pelo incremento em área transversal ser fortemente influenciado pelo diâmetro inicial da árvore.

Tabela 2. Incremento em área transversal por classe diamétrica para o período 1979-2000.

Table 2. Individual basal area increment per diameter classes in 1979-2000 period.

\begin{tabular}{|c|c|c|c|c|c|c|c|}
\hline $\begin{array}{c}\text { Classe de DAP } \\
(\mathrm{cm})\end{array}$ & $\begin{array}{c}\mathrm{N}^{\mathbf{0}} \text { de } \\
\text { Árvores } \\
\text { (9 ha) }\end{array}$ & $\begin{array}{c}\text { Média } \\
\left(\mathrm{m}^{2}\right)\end{array}$ & $\begin{array}{l}\text { Mediana } \\
\left(\mathrm{m}^{2}\right)\end{array}$ & $\begin{array}{c}\text { Mínimo } \\
\left(\mathrm{m}^{2}\right)\end{array}$ & $\begin{array}{c}\text { Máximo } \\
\left(\mathrm{m}^{2}\right)\end{array}$ & $\begin{array}{c}\text { Desvio } \\
\text { Padrão } \\
\left(\mathrm{m}^{2}\right)\end{array}$ & $\begin{array}{l}\text { C.V. } \\
(\%)\end{array}$ \\
\hline $20,0-30,0$ & 685 & 0,02318 & 0,01805 & $-0,00790$ & 0,11995 & 0,01984 & 85,59 \\
\hline $30,0-40,0$ & 472 & 0,03170 & 0,02773 & $-0,02527$ & 0,15274 & 0,02562 & 80,82 \\
\hline $40,0-50,0$ & 301 & 0,05528 & 0,05235 & $-0,01031$ & 0,19406 & 0,03475 & 62,86 \\
\hline $50,0-60,0$ & 106 & 0,06480 & 0,06473 & $-0,01417$ & 0,17786 & 0,04094 & 63,18 \\
\hline $60,0-70,0$ & 30 & 0,07972 & 0,08373 & 0,00724 & 0,15109 & 0,04078 & 51,16 \\
\hline $70,0-80,0$ & 12 & 0,09762 & 0,08394 & $-0,02095$ & 0,20918 & 0,06470 & 66,28 \\
\hline $80,0-90,0$ & 6 & 0,08580 & 0,08453 & $-0,01854$ & 0,20784 & 0,07676 & 89,47 \\
\hline $90,0-100,0$ & 3 & 0,10136 & 0,06753 & 0,01608 & 0,22049 & 0,10632 & 104,89 \\
\hline $100,0-110,0$ & 3 & 0,10467 & 0,09747 & 0,08679 & 0,12975 & 0,02237 & 21,37 \\
\hline $110,0-120,0$ & 2 & 0,01025 & 0,01025 & $-0,02680$ & 0,04729 & 0,05239 & 511,35 \\
\hline Total & 1620 & & & & & & \\
\hline
\end{tabular}

Da mesma forma que verificado na análise dos incrementos diamétricos, as classes diamétricas intermediárias apresentaram os maiores incrementos em área transversal, sendo que as classes inferiores apresentaram os menores valores (Tabela 2).

Quando o objeto da análise passa a ser as parcelas, conforme pode ser observado na Tabela 3, constata-se que a tendência dos incrementos diamétricos em apresentarem distribuições assimétricas à direita é mantida. Todas as parcelas apresentaram valores medianos inferiores aos valores da média aritmética.

$\mathrm{O}$ incremento diamétrico foi diferenciado entre as parcelas, sendo que a parcela 10 apresentou o menor valor mediano $(3,80 \mathrm{~cm})$, seguido pela parcela $18(4,80 \mathrm{~cm})$. Já a parcela 1 apresentou o maior valor mediano para o incremento diamétrico $(6,60 \mathrm{~cm})$. No geral, todos as parcelas apresentaram 
incrementos medianos próximos a 5,30 cm, que é a mediana do incremento diamétrico da floresta. Um fato interessante é que a parcela 10, que apresentou o menor incremento mediano, foi a parcela com a maior variabilidade, com seu coeficiente de variação sendo de $80,00 \%$. Já a parcela 1 , que teve o maior incremento, apresentou a menor variabilidade, com seu coeficiente de variação sendo de $61,43 \%$.

Tabela 3. Incremento em diâmetro por parcela para o período 1979-2000.

Table 3. Diameter increment per plot in 1979-2000 period.

\begin{tabular}{cccccccc}
\hline $\mathbf{N}^{\mathbf{0}}$ Parcela & $\begin{array}{c}\mathbf{N}^{\mathbf{0}} \mathbf{d e} \\
\text { Árvores } \\
\mathbf{( 9} \mathbf{~ h a})\end{array}$ & $\begin{array}{c}\text { Média } \\
\mathbf{( c m )}\end{array}$ & $\begin{array}{c}\text { Mediana } \\
\mathbf{( c m )}\end{array}$ & $\begin{array}{c}\text { Mínimo } \\
\mathbf{( c m )}\end{array}$ & $\begin{array}{c}\text { Máximo } \\
(\mathbf{c m})\end{array}$ & $\begin{array}{c}\text { Desvio } \\
\text { Padrão } \\
(\mathbf{c m})\end{array}$ & $\begin{array}{c}\mathbf{C} . \mathbf{} \\
(\mathbf{\%})\end{array}$ \\
\hline 1 & 115 & 6,80 & 6,60 & $-1,7$ & 18,0 & 4,18 & 61,43 \\
6 & 182 & 5,84 & 5,10 & $-1,6$ & 21,3 & 4,42 & 75,63 \\
7 & 218 & 5,78 & 5,45 & $-2,0$ & 16,5 & 3,89 & 67,27 \\
10 & 197 & 4,78 & 3,80 & $-2,1$ & 16,0 & 3,82 & 80,00 \\
17 & 184 & 6,04 & 5,15 & $-1,4$ & 21,1 & 4,42 & 73,25 \\
18 & 204 & 5,18 & 4,80 & $-1,5$ & 15,2 & 3,36 & 64,95 \\
21 & 152 & 5,75 & 5,60 & $-2,4$ & 23,9 & 4,25 & 73,78 \\
22 & 174 & 6,19 & 5,85 & $-0,5$ & 21,7 & 4,04 & 65,39 \\
30 & 194 & 5,89 & 5,15 & $-5,3$ & 19,3 & 4,36 & 73,94 \\
\hline Total & $\mathbf{1 6 2 0}$ & & & & & & \\
\hline
\end{tabular}

Como o incremento diamétrico é calculado com base nas árvores que permaneceram vivas no período, o maior incremento mostrado pela parcela 1 é devido, provavelmente, ao incêndio ocorrido nessa parcela em 1982. Tal fato promoveu uma liberação de espaço, devido à morte de algumas árvores - essa parcela apresentou o maior percentual de árvores mortas -, fazendo com que as árvores remanescentes pudessem crescer sob uma pressão competitiva menor, ou seja, a parcela 1 comportou-se como um povoamento desbastado. Isso pode ser confirmado através da análise do incremento em área transversal, conforme a Tabela 4, onde a parcela 1 apresentou maior incremento mediano.

O desempenho das parcelas em relação à área transversal foi similar ao apresentado pelos incrementos diamétricos. Contudo, os incrementos em área transversal tiveram uma variabilidade maior, como mostra a Tabela 4.

Tabela 4. Incremento em área transversal por parcela para o período 1979-2000.

Table 4. Individual basal area increment per plot in 1979-2000 period.

\begin{tabular}{|c|c|c|c|c|c|c|c|}
\hline $\mathbf{N}^{0}$ Parcela & $\begin{array}{c}\mathbf{N}^{0} \text { de } \\
\text { Árvores } \\
\text { (9 ha) }\end{array}$ & $\begin{array}{c}\text { Média } \\
\left(\mathbf{m}^{2}\right)\end{array}$ & $\begin{array}{l}\text { Mediana } \\
\qquad\left(\mathrm{m}^{2}\right)\end{array}$ & $\begin{array}{c}\text { Mínimo } \\
\left(\mathbf{m}^{2}\right)\end{array}$ & $\begin{array}{c}\text { Máximo } \\
\left(\mathbf{m}^{2}\right)\end{array}$ & $\begin{array}{c}\text { Desvio } \\
\text { Padrão } \\
\left(\mathbf{m}^{2}\right) \\
\end{array}$ & $\begin{array}{l}\text { C.V. } \\
(\%)\end{array}$ \\
\hline 1 & 115 & 0,04240 & 0,03514 & $-0,00712$ & 0,17786 & 0,03361 & 79,27 \\
\hline 6 & 182 & 0,03584 & 0,02658 & $-0,01237$ & 0,20918 & 0,03478 & 97,05 \\
\hline 7 & 218 & 0,03468 & 0,02706 & $-0,01417$ & 0,22049 & 0,03138 & 90,51 \\
\hline 10 & 197 & 0,03111 & 0,02127 & $-0,02095$ & 0,14948 & 0,03032 & 97,45 \\
\hline 17 & 184 & 0,04002 & 0,03004 & $-0,00512$ & 0,20784 & 0,03618 & 90,40 \\
\hline 18 & 204 & 0,03293 & 0,02631 & $-0,01031$ & 0,12912 & 0,02725 & 82,75 \\
\hline 21 & 152 & 0,03422 & 0,02930 & $-0,01237$ & 0,11995 & 0,02771 & 80,99 \\
\hline 22 & 174 & 0,04028 & 0,03316 & $-0,00167$ & 0,18015 & 0,03410 & 84,67 \\
\hline 30 & 194 & 0,03961 & 0,03026 & $-0,02680$ & 0,19156 & 0,03699 & 93,37 \\
\hline Total & 1620 & & & & & & \\
\hline
\end{tabular}

O crescimento/incremento em diâmetro e em área transversal também foi analisado em função das variáveis qualitativas vitalidade, posição sociológica e qualidade do fuste, conforme está apresentado nas Tabelas 5 a 10.

A análise das Tabelas 5 e 6 mostra que, tanto para o incremento diamétrico como para o incremento em área transversal, as classes de vitalidade tiveram comportamentos bastante diferenciados. 
Tabela 5. Incremento em diâmetro por classe de vitalidade para o período 1979-2000.

Table 5. Diameter increment per vitality classes in 1979-2000 period.

\begin{tabular}{lccccccc}
\hline Vitalidade & $\begin{array}{c}\mathbf{N}^{\mathbf{0}} \mathbf{d e} \\
\text { Árvores } \\
\mathbf{( 9} \mathbf{~ h a})\end{array}$ & $\begin{array}{c}\text { Média } \\
\mathbf{( c m )}\end{array}$ & $\begin{array}{c}\text { Mediana } \\
\mathbf{( c m )}\end{array}$ & $\begin{array}{c}\text { Mínimo } \\
\mathbf{( c m )}\end{array}$ & $\begin{array}{c}\text { Máximo } \\
\mathbf{( c m )}\end{array}$ & $\begin{array}{c}\text { Desvio } \\
\text { Padrão } \\
(\mathbf{c m})\end{array}$ & $\begin{array}{c}\text { C.V. } \\
\mathbf{( \% )}\end{array}$ \\
\hline Boa & 1247 & 6,36 & 6,10 & $-5,3$ & 23,9 & 4,08 & 64,14 \\
Média & 282 & 3,93 & 3,30 & $-2,1$ & 18,8 & 3,46 & 87,97 \\
Ruim & 91 & 2,95 & 2,10 & $-1,6$ & 15,5 & 3,30 & 112,21 \\
\hline Total & $\mathbf{1 6 2 0}$ & & & & & &
\end{tabular}

No caso do incremento diamétrico (Tabela 5), nota-se que quanto melhor a vitalidade da árvore, maior seu incremento diamétrico, a ponto de o incremento mediano na classe de melhor vitalidade $(6,10$ $\mathrm{cm})$ ser 1,8 vezes maior que o da classe de vitalidade intermediária $(3,30 \mathrm{~cm})$ e 2,9 vezes maior que o da classe de vitalidade inferior $(2,10 \mathrm{~cm})$. Além disto, o comportamento das árvores com melhor vitalidade, em relação ao incremento diamétrico, é mais homogêneo (C.V. $=64,14 \%$ ) que o apresentado pelas classes de pior vitalidade (C.V. $=87,97 \%$ e $112,21 \%)$.

A Tabela 6 mostra que, apesar do comportamento semelhante, o incremento em área transversal foi mais influenciado pela classificação da vitalidade do que o incremento diamétrico.

Tabela 6. Incremento em área transversal por classe de vitalidade para o período 1979-2000.

Table 6. Individual basal area increment per vitality classes in 1979-2000 period.

\begin{tabular}{|c|c|c|c|c|c|c|c|}
\hline Vitalidade & $\begin{array}{c}\mathbf{N}^{0} \text { de } \\
\text { Árvores } \\
\text { (9 ha) }\end{array}$ & $\begin{array}{c}\text { Média } \\
\left(\mathrm{m}^{2}\right)\end{array}$ & $\begin{array}{c}\text { Mediana } \\
\left(\mathrm{m}^{2}\right)\end{array}$ & $\begin{array}{c}\text { Mínimo } \\
\left(\mathrm{m}^{2}\right)\end{array}$ & $\begin{array}{c}\text { Máximo } \\
\left(\mathrm{m}^{2}\right)\end{array}$ & $\begin{array}{c}\text { Desvio } \\
\text { Padrão } \\
\left(\mathbf{m}^{2}\right)\end{array}$ & $\begin{array}{l}\text { C.V. } \\
(\%)\end{array}$ \\
\hline Boa & 1247 & 0,04128 & 0,03384 & $-0,02527$ & 0,22049 & 0,03358 & 81,36 \\
\hline Média & 282 & 0,02139 & 0,01531 & $-0,02680$ & 0,12975 & 0,02249 & 105,13 \\
\hline Ruim & 91 & 0,01711 & 0,01023 & $-0,00666$ & 0,19156 & 0,02565 & 149,93 \\
\hline Total & 1620 & & & & & & \\
\hline
\end{tabular}

O incremento mediano em área transversal da classe de melhor vitalidade $\left(0,03384 \mathrm{~m}^{2}\right)$ foi 2,2 vezes maior que o da classe de vitalidade intermediária $\left(0,02139 \mathrm{~m}^{2}\right)$ e 3,3 vezes maior que o da classe de vitalidade inferior $\left(0,01711 \mathrm{~m}^{2}\right)$. Da mesma forma que para o incremento diamétrico, o comportamento das árvores com melhor vitalidade, em relação ao incremento em área transversal, foi mais homogêneo $(C . V .=81,36 \%)$ que o apresentado pelas classes de pior vitalidade (C.V. $=105,13 \%$ e 149,93\%).

Nas Tabelas 7 e 8 estão apresentados os valores dos incrementos por posição sociológica para o diâmetro e para a área transversal, respectivamente.

Tabela 7. Incremento em diâmetro por estrato para o período 1979-2000.

Table 7. Diameter increment per stratum in 1979-2000 period.

\begin{tabular}{lccccccc}
\hline Estrato & $\begin{array}{c}\mathbf{N}^{\mathbf{0}} \mathbf{d e} \\
\mathbf{( 9 ~ h a )}\end{array}$ & $\begin{array}{c}\text { Média } \\
\mathbf{( c m )}\end{array}$ & $\begin{array}{c}\text { Mediana } \\
\mathbf{( c m )}\end{array}$ & $\begin{array}{c}\text { Mínimo } \\
\mathbf{( c m )}\end{array}$ & $\begin{array}{c}\text { Máximo } \\
\mathbf{( c m )}\end{array}$ & $\begin{array}{c}\text { Desvio } \\
\text { Padrão } \\
(\mathbf{c m})\end{array}$ & $\begin{array}{c}\text { C.V. } \\
\mathbf{\%}\end{array}$ \\
\hline Superior & 523 & 7,34 & 7,20 & $-1,5$ & 21,1 & 3,82 & 52,08 \\
Médio & 586 & 5,65 & 5,10 & $-2,4$ & 21,7 & 4,04 & 71,46 \\
Inferior & 511 & 4,22 & 3,30 & $-5,3$ & 23,9 & 3,83 & 90,81 \\
\hline Total & $\mathbf{1 6 2 0}$ & & & & & &
\end{tabular}

Nota-se, na Tabela 7, que a posição sociológica influencia grandemente o incremento diamétrico, pois quanto mais superior for o estrato em que a árvore se encontra, maior tende a ser seu incremento diamétrico. A mediana dos incrementos das árvores do estrato inferior foi de $3,30 \mathrm{~cm}$, para o estrato médio foi de $5,10 \mathrm{~cm}$ e para o estrato superior foi de $7,20 \mathrm{~cm}$. Por outro lado, a variabilidade teve comportamento oposto. $\mathrm{O}$ estrato inferior apresentou a maior variabilidade $(90,81 \%)$, sendo que o estrato 
médio teve variação de $71,46 \%$ e o estrato superior $52,08 \%$. Conforme comentado anteriormente, as árvores do estrato superior estão numa posição em que as condições de aporte de energia solar, que afetam diretamente o crescimento, são mais homogêneas do que as condições às quais as árvores dos estratos inferiores estão sujeitas. Além disto, há uma menor quantidade de espécies que atingem o estrato superior comparada ao número de espécies que ocorrem nos estratos inferiores. Portanto, além de receber energia de forma mais homogênea e constante, o estrato superior é menos heterogêneo em termos de espécies, o que reflete em padrões de crescimento mais homogêneos.

Todas as observações feitas em relação ao incremento diamétrico confirmam-se na análise do incremento em área transversal (Tabela 8).

Tabela 8. Incremento em área transversal por estrato para o período 1979-2000.

Table 8. Individual basal area per stratum in 1979-2000 period.

\begin{tabular}{|c|c|c|c|c|c|c|c|}
\hline Estrato & $\begin{array}{c}\mathbf{N}^{\mathbf{0}} \text { de } \\
\text { Árvores } \\
\text { (9 ha) }\end{array}$ & $\begin{array}{c}\text { Média } \\
\left(\mathbf{m}^{2}\right)\end{array}$ & $\begin{array}{l}\text { Mediana } \\
\quad\left(\mathbf{m}^{2}\right)\end{array}$ & $\begin{array}{c}\text { Mínimo } \\
\left(\mathbf{m}^{2}\right)\end{array}$ & $\begin{array}{c}\text { Máximo } \\
\left(\mathrm{m}^{2}\right)\end{array}$ & $\begin{array}{c}\text { Desvio } \\
\text { Padrão } \\
\left(\mathrm{m}^{2}\right)\end{array}$ & $\begin{array}{l}\text { C.V. } \\
(\%)\end{array}$ \\
\hline Superior & 523 & 0,05402 & 0,04820 & $-0,01031$ & 0,22049 & 0,03718 & 68,83 \\
\hline Médio & 586 & 0,03394 & 0,02843 & $-0,02680$ & 0,18015 & 0,02879 & 84,84 \\
\hline Inferior & 511 & 0,02138 & 0,01484 & $-0,02527$ & 0,14301 & 0,02196 & 102,73 \\
\hline Total & 1620 & & & & & & \\
\hline
\end{tabular}

Em ambas as análises, verifica-se um comportamento assimétrico à direita da distribuição dos incrementos dentro dos estratos, pois sempre o valor da média é superior ao valor da mediana.

Da mesma forma que para as outras variáveis qualitativas, o incremento diamétrico e em área transversal é influenciado pela qualidade do fuste, como mostram as Tabelas 9 e 10.

Tabela 9. Incremento em diâmetro por classe de qualidade de fuste para o período 1979-2000.

Table 9. Diameter increment per stem quality in 1979-2000 period.

\begin{tabular}{lccccccc}
\hline $\begin{array}{l}\text { Qualidade do } \\
\text { Fuste }\end{array}$ & $\begin{array}{c}\mathbf{N}^{\mathbf{0}} \mathbf{d e} \\
\text { Árvores } \\
\mathbf{( 9} \mathbf{~ h a})\end{array}$ & $\begin{array}{c}\text { Média } \\
\mathbf{( c m )}\end{array}$ & $\begin{array}{c}\text { Mediana } \\
\mathbf{( c m )}\end{array}$ & $\begin{array}{c}\text { Mínimo } \\
\mathbf{( c m )}\end{array}$ & $\begin{array}{c}\text { Máximo } \\
\mathbf{( c m )}\end{array}$ & $\begin{array}{c}\text { Desvio } \\
\text { Padrão } \\
\mathbf{( c m )}\end{array}$ & $\begin{array}{c}\text { C.V. } \\
\mathbf{( \% )}\end{array}$ \\
\hline Boa & 901 & 6,75 & 6,60 & $-2,4$ & 21,3 & 3,94 & 58,29 \\
Média & 414 & 5,03 & 4,15 & $-5,3$ & 23,9 & 4,11 & 81,70 \\
Ruim & 305 & 3,74 & 2,80 & $-2,1$ & 21,1 & 3,59 & 96,03 \\
\hline Total & $\mathbf{1 6 2 0}$ & & & & & & \\
\hline
\end{tabular}

Na Tabela 9, verifica-se que quanto melhor a qualidade do fuste, maior é o incremento apresentado. A classe que representa a melhor qualidade de fuste apresentou incremento diamétrico mediano igual a $6,60 \mathrm{~cm}$, a classe de qualidade de fuste intermediária mostrou um incremento diamétrico de $5,03 \mathrm{~cm}$ e a classe de qualidade inferior apresentou incremento igual a $2,80 \mathrm{~cm}$. Do mesmo modo que para todas as outras variáveis qualitativas, quanto maior o incremento apresentado por determinada classe, menor é sua variabilidade.

A Tabela 10 apenas confirma as observações feitas em relação ao incremento diamétrico, considerando, contudo, o incremento periódico em área transversal.

O comportamento dos incrementos em relação à qualidade de fuste indica que essa variável, indiretamente, exprime o potencial de crescimento da árvore, ou seja, quanto melhor for o fuste, menos estará sujeito a quedas de casca e apodrecimento e maior será a probabilidade de apresentar um crescimento maior, comparado a um fuste defeituoso.

A Tabela 11 apresenta os valores dos incrementos periódicos em diâmetros por espécie. Apesar de Syagrus romanzoffiana aparecer nas tabelas relativas aos incrementos, constitui-se numa espécie que não forma xilema secundário, sendo seu tronco basicamente formado por tecido parenquimático. Portanto, os valores de incremento apresentados por essa espécie carecem de significado prático, não podendo servir como termo de comparação com outras espécies. Além disso, é uma espécie na qual apenas dois indivíduos permaneceram vivos no período, o que também comprometeria análises mais profundas. 
Tabela 10.Incremento em área transversal por qualidade de fuste para o período 1979-2000.

Table 10. Individual basal area per stem quality in 1979-2000 period.

\begin{tabular}{|c|c|c|c|c|c|c|c|}
\hline $\begin{array}{l}\text { Qualidade } \\
\text { do Fuste }\end{array}$ & $\begin{array}{l}\mathbf{N}^{0} \text { de } \\
\text { Árvores } \\
(9 \text { ha) }\end{array}$ & $\begin{array}{c}\text { Média } \\
\left(\mathbf{m}^{2}\right)\end{array}$ & $\begin{array}{l}\text { Mediana } \\
\quad\left(\mathrm{m}^{2}\right)\end{array}$ & $\begin{array}{c}\text { Mínimo } \\
\left(\mathbf{m}^{2}\right)\end{array}$ & $\begin{array}{c}\text { Máximo } \\
\left(\mathbf{m}^{2}\right)\end{array}$ & $\begin{array}{c}\text { Desvio } \\
\text { Padrão } \\
\left(\mathrm{m}^{2}\right)\end{array}$ & $\begin{array}{c}\text { C.V. } \\
\%\end{array}$ \\
\hline Boa & 901 & 0,04539 & 0,03983 & $-0,02095$ & 0,22049 & 0,03397 & 74,83 \\
\hline Média & 414 & 0,02874 & 0,02081 & $-0,02527$ & 0,19156 & 0,02883 & 100,29 \\
\hline Ruim & 305 & 0,02054 & 0,01262 & $-0,02680$ & 0,19406 & 0,02421 & 117,90 \\
\hline
\end{tabular}

Das espécies com densidade superior a 5 indivíduos, a que mostrou o maior incremento diamétrico em termos medianos foi a Nectandra megapotamica, com 12,20 cm de incremento no período analisado. Adicionalmente, foi uma das espécies com a menor variabilidade nos incrementos $(36,55 \%)$. Outras lauráceas, independentemente do caráter pioneiro, também apresentaram altos valores medianos de incremento diamétrico, como Ocotea porosa $(7,30 \mathrm{~cm})$, Cinnamomum vesiculosum $(7,20 \mathrm{~cm})$ e Cinnamomum sellowianum $(7,10 \mathrm{~cm})$. A araucária apresentou incremento mediano de $6,60 \mathrm{~cm}$ para o período analisado. Deve-se destacar, ainda, a Cedrela fissilis, que apresentou o segundo maior valor de incremento $(9,20 \mathrm{~cm})$.

Por outro lado, Eugenia sp. e Allophylus edulis foram as espécies que menos cresceram no período, com medianas iguais a $1,50 \mathrm{~cm}$ e com as maiores variabilidades dos incrementos, $128,71 \% \mathrm{e}$ $192,98 \%$, respectivamente. De modo geral, ao contrário das lauráceas, as mirtáceas apresentaram incrementos diamétricos diminutos. Além de Eugenia sp., Myrcia obtecta, com incremento mediano igual a 1,70 cm, e Eugenia involucrata, com mediana igual a $1,90 \mathrm{~cm}$, foram as espécies com os menores valores de incremento diamétrico. Campomanesia xanthocarpa foi uma das poucas mirtáceas com incremento mediano superior a $2 \mathrm{~cm}(4,15 \mathrm{~cm})$, ainda assim, inferior ao incremento da laurácea que menos cresceu: Ocotea corymbosa, com incremento mediano igual a 4,65 cm.

Entre as aqüifoliáceas, o melhor desempenho foi de Ilex paraguariensis, com 2,60 cm de incremento mediano. A pioneira Rapanea ferruginea apresentou desempenho superior à média, com 6,30 $\mathrm{cm}$ de incremento mediano.

O comportamento dos incrementos em área transversal seguiram os padrões observados para os incrementos em diâmetro, conforme mostra a Tabela 12. Contudo, os incrementos em área transversal apresentaram uma maior variabilidade. Por exemplo, Nectandra megapotamica, que foi a espécie com o maior incremento mediano em área transversal $\left(0,05246 \mathrm{~m}^{2}\right)$, apresentou uma variabilidade de $69,55 \%$, contra $36,55 \%$ de variabilidade considerando-se o incremento diamétrico.

Os valores dos incrementos periódicos anuais por espécie, em relação ao diâmetro e à área transversal, estão apresentados nas Tabelas 13 e 14, respectivamente. Os padrões de crescimento do incremento periódico anual são idênticos aos observados na análise do incremento periódico (19792000), discutidos anteriormente.

\section{Balanço da dinâmica em termos da ocupação do espaço}

A análise usual da dinâmica, principalmente relacionada ao ingresso e à mortalidade, concentrase basicamente no número de indivíduos. Entretanto, tal análise nem sempre fornece resultados realistas, visto que o balanço ingresso/mortalidade é uma questão muito mais de espaço do que de número de árvores. Na Tabela 15 estão apresentados os valores de área basal por parcela e para a floresta ( $9 \mathrm{ha}) \mathrm{em}$ função das árvores mortas, dos ingressos e das árvores que permaneceram vivas.

Verifica-se que as árvores que permaneceram vivas durante o período estudado produziram um incremento em área basal igual a $59,06310 \mathrm{~m}^{2}$, o qual, somado à área basal dos ingressos $\left(27,37253 \mathrm{~m}^{2}\right) \mathrm{e}$ subtraído da área basal das árvores mortas $\left(41,13014 \mathrm{~m}^{2}\right)$, proporcionou um incremento líquido de $45,30549 \mathrm{~m}^{2}$ na área basal dos 9 talhões estudados, que representa um incremento proporcional de $21,40 \%$. Portanto, pode-se dizer que o aporte líquido de área basal nos 9 ha da floresta entre 1979 e 2000 foi quase igual à soma da área basal de duas parcelas (2 ha). Essa constatação confirma o fato de que a floresta amadureceu no período estudado, pois se houve crescimento líquido havia espaço de crescimento necessário para tal, ou seja, a floresta não estava completamente estocada em 1979. 
A análise das parcelas leva à mesma conclusão, pois todas apresentaram incrementos líquidos. A parcela 7 foi a que apresentou a maior taxa de incremento líquido, tanto em termos absolutos $\left(9,48777 \mathrm{~m}^{2}\right)$ como em termos percentuais $(43,20 \%)$. A parcela 1 foi a que apresentou a menor taxa de incremento líquido absoluto $\left(2,64091 \mathrm{~m}^{2}\right)$. Já a parcela 30 teve o menor incremento líquido em termos percentuais $(12,58 \%)$.

Tabela 11. Incremento em diâmetro por espécie para o período 1979-2000.

Table 11. Diameter increment per specie in 1979-2000 period.

\begin{tabular}{|c|c|c|c|c|c|c|c|}
\hline Espécie & $\begin{array}{c}\mathbf{N}^{0} \text { de } \\
\text { Árvores } \\
(9 \text { ha) }\end{array}$ & $\begin{array}{l}\text { Média } \\
(\mathrm{cm})\end{array}$ & $\begin{array}{l}\text { Mediana } \\
\quad \text { (cm) }\end{array}$ & $\begin{array}{c}\text { Mínimo } \\
\text { (cm) }\end{array}$ & $\begin{array}{l}\text { Máximo } \\
\text { (cm) }\end{array}$ & $\begin{array}{c}\text { Desvio } \\
\text { Padrão } \\
\text { (cm) }\end{array}$ & $\begin{array}{l}\text { C.V. } \\
\text { (\%) }\end{array}$ \\
\hline Albizia sp. & 1 & 10,10 & - & 10,10 & 10,10 & - & - \\
\hline Allophylus edulis & 5 & 1,04 & 1,50 & $-2,10$ & 3,30 & 2,01 & 192,98 \\
\hline Araucaria angustifolia & 870 & 6,77 & 6,60 & $-2,40$ & 23,90 & 3,95 & 58,30 \\
\hline Campomanesia xanthocarpa & 70 & 4,16 & 4,15 & $-1,70$ & 15,60 & 3,13 & 75,25 \\
\hline Capsicodendron dinisii & 67 & 3,01 & 3,20 & $-1,70$ & 8,80 & 2,39 & 79,29 \\
\hline Casearia inaequilatera & 3 & 4,83 & 3,90 & 1,40 & 9,20 & 3,98 & 82,40 \\
\hline Cedrela fissilis & 8 & 9,99 & 9,20 & 5,20 & 19,30 & 4,63 & 46,35 \\
\hline Cinnamoтит sellowianum & 5 & 8,94 & 7,10 & 5,60 & 13,10 & 3,29 & 36,85 \\
\hline Cinnaтотит vesiculosum & 9 & 6,61 & 7,20 & 1,10 & 13,70 & 3,91 & 59,12 \\
\hline Citronella paniculata & 1 & $-1,20$ & - & $-1,20$ & $-1,20$ & - & - \\
\hline Drimys brasiliensis & 1 & 2,70 & - & 2,70 & 2,70 & - & - \\
\hline Erythroxylum deciduum & 7 & 2,51 & 2,90 & $-0,20$ & 4,40 & 1,47 & 58,43 \\
\hline Eugenia hyemalis & 3 & 1,23 & 1,20 & 0,50 & 2,00 & 0,75 & 60,86 \\
\hline Eugenia involucrata & 16 & 2,53 & 1,90 & 0,00 & 7,00 & 2,13 & 84,38 \\
\hline Eugenia sp. & 15 & 1,29 & 1,50 & $-1,50$ & 3,20 & 1,66 & 128,71 \\
\hline Eugenia speciosa & 3 & 1,70 & 1,50 & 0,60 & 3,00 & 1,21 & 71,32 \\
\hline Eugenia uniflora & 2 & 2,45 & 2,45 & 2,00 & 2,90 & 0,64 & 25,98 \\
\hline Gochnatia polymorpha & 2 & 2,65 & 2,65 & $-0,90$ & 6,20 & 5,02 & 189,45 \\
\hline Gomidesia sellowiana & 3 & 5,70 & 6,10 & 3,10 & 7,90 & 2,42 & 42,54 \\
\hline Ilex brevicuspis & 9 & 2,72 & 2,50 & $-0,30$ & 7,00 & 2,40 & 88,20 \\
\hline Ilex dumosa & 40 & 2,18 & 1,60 & $-0,70$ & 12,30 & 2,54 & 116,33 \\
\hline Ilex paraguariensis & 5 & 3,18 & 2,60 & 2,00 & 4,70 & 1,27 & 40,05 \\
\hline Jacaranda puberula & 3 & 1,93 & 1,50 & 1,10 & 3,20 & 1,12 & 57,67 \\
\hline Lamanonia speciosa & 2 & $-0,15$ & $-0,15$ & $-0,40$ & 0,10 & 0,35 & $-235,70$ \\
\hline Lithraea brasiliensis & 26 & 3,45 & 3,45 & $-5,30$ & 11,90 & 3,51 & 101,83 \\
\hline Luehea divaricata & 1 & 6,20 & - & 6,20 & 6,20 & - & - \\
\hline Matayba elaeagnoides & 163 & 3,56 & 2,50 & $-2,10$ & 21,70 & 3,49 & 98,05 \\
\hline Maytenus ilicifolia & 1 & 2,20 & - & 2,20 & 2,20 & - & 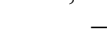 \\
\hline Myrcia obtecta & 11 & 2,42 & 1,70 & $-0,60$ & 6,70 & 2,49 & 103,10 \\
\hline Nectandra grandiflora & 76 & 6,41 & 5,70 & $-0,10$ & 18,00 & 4,02 & 62,69 \\
\hline Nectandra megapotamica & 5 & 11,08 & 12,20 & 5,10 & 16,10 & 4,05 & 36,55 \\
\hline Ocotea corymbosa & 36 & 5,67 & 4,65 & 0,00 & 21,10 & 4,06 & 71,68 \\
\hline Ocotea porosa & 78 & 7,74 & 7,30 & $-1,50$ & 21,30 & 4,26 & 55,13 \\
\hline Ocotea puberula & 9 & 8,49 & 6,20 & 1,80 & 18,80 & 5,87 & 69,14 \\
\hline Persea sp. & 1 & 2,80 & - & 2,80 & 2,80 & - & - \\
\hline Prunus brasiliensis & 21 & 5,90 & 6,20 & $-0,20$ & 18,00 & 4,30 & 72,81 \\
\hline Rapanea ferruginea & 21 & 6,51 & 6,30 & $-0,30$ & 12,50 & 3,29 & 50,47 \\
\hline Schinus terebinthifolius & 2 & 1,15 & 1,15 & $-1,60$ & 3,90 & 3,89 & 338,18 \\
\hline Sebastiania brasiliensis & 2 & 2,50 & 2,50 & 1,80 & 3,20 & 0,99 & 39,60 \\
\hline Sloanea lasiocoma & 1 & 3,40 & - & 3,40 & 3,40 & - & - \\
\hline Syagrus romanzoffiana & 2 & 0,35 & 0,35 & $-0,10$ & 0,80 & 0,64 & 181,83 \\
\hline Vitex megapotamica & 1 & 1,60 & - & 1,60 & 1,60 & - & - \\
\hline Zanthoxylum kleinii & 8 & 4,10 & 3,30 & 0,20 & 7,90 & 2,67 & 65,02 \\
\hline Mirtaceae 1 & 3 & 3,53 & 3,40 & 2,20 & 5,00 & 1,40 & 39,76 \\
\hline Não-identificadas & 2 & 4,10 & 4,10 & 2,50 & 5,70 & 2,26 & 55,19 \\
\hline Total & 1620 & & & & & & \\
\hline
\end{tabular}


Tabela 12. Incremento em área transversal por espécie para o período 1979-2000.

Table 12. Individual basal area increment per specie in 1979-2000 period.

\begin{tabular}{|c|c|c|c|c|c|c|c|}
\hline Espécie & $\begin{array}{c}\mathbf{N}^{0} \text { de } \\
\text { Árvores } \\
\text { (9 ha) }\end{array}$ & $\begin{array}{c}\text { Média } \\
\left(\mathrm{m}^{2}\right)\end{array}$ & $\begin{array}{c}\text { Mediana } \\
\left(\mathbf{m}^{2}\right)\end{array}$ & $\begin{array}{c}\text { Mínimo } \\
\left(\mathbf{m}^{2}\right)\end{array}$ & $\underset{\left(\mathbf{m}^{2}\right)}{\text { Máximo }}$ & $\begin{array}{c}\text { Desvio } \\
\text { Padrão } \\
\left(\mathbf{m}^{2}\right)\end{array}$ & $\begin{array}{l}\text { C.V. } \\
(\%)\end{array}$ \\
\hline Albizia sp. & 1 & 0,04291 & - & 0,04291 & 0,04291 & - & - \\
\hline Allophylus edulis & 5 & 0,00385 & 0,00583 & $-0,00790$ & 0,01200 & 0,00736 & 191,33 \\
\hline Araucaria angustifolia & 870 & 0,04510 & 0,03957 & $-0,02095$ & 0,22049 & 0,03404 & 75,49 \\
\hline Campomanesia xanthocarpa & 70 & 0,01951 & 0,01771 & $-0,00712$ & 0,07792 & 0,01580 & 80,96 \\
\hline Capsicodendron dinisii & 67 & 0,01538 & 0,01396 & $-0,00805$ & 0,06849 & 0,01415 & 92,00 \\
\hline Casearia inaequilatera & 3 & 0,02672 & 0,01988 & 0,01027 & 0,05000 & 0,02073 & 77,59 \\
\hline Cedrela fissilis & 8 & 0,06101 & 0,04844 & 0,02489 & 0,14749 & 0,04184 & 68,58 \\
\hline Cinnamomum sellowianum & 5 & 0,05094 & 0,04801 & 0,04076 & 0,06530 & 0,00944 & 18,53 \\
\hline Cinnamoтum vesiculosum & 9 & 0,03710 & 0,03496 & 0,00735 & 0,06288 & 0,01958 & 52,78 \\
\hline Citronella paniculata & 1 & $-0,00630$ & - & $-0,00630$ & $-0,00630$ & - & - \\
\hline Drimys brasiliensis & 1 & 0,01436 & - & 0,01436 & 0,01436 & - & - \\
\hline Erythroxylum deciduum & 7 & 0,00978 & 0,01023 & $-0,00069$ & 0,01880 & 0,00618 & 63,19 \\
\hline Eugenia hyemalis & 3 & 0,00418 & 0,00426 & 0,00167 & 0,00660 & 0,00247 & 59,04 \\
\hline Eugenia involucrata & 16 & 0,01147 & 0,00755 & 0,00000 & 0,02948 & 0,00973 & 84,81 \\
\hline Eugenia sp. & 15 & 0,00482 & 0,00560 & $-0,00666$ & 0,01249 & 0,00643 & 133,21 \\
\hline Eugenia speciosa & 3 & 0,00927 & 0,00748 & 0,00267 & 0,01767 & 0,00766 & 82,61 \\
\hline Eugenia uniflora & 2 & 0,00972 & 0,00972 & 0,00738 & 0,01205 & 0,00330 & 33,96 \\
\hline Gochnatia polymorpha & 2 & 0,02072 & 0,02072 & $-0,00736$ & 0,04879 & 0,03970 & 191,65 \\
\hline Gomidesia sellowiana & 3 & 0,02208 & 0,02209 & 0,01195 & 0,03220 & 0,01012 & 45,85 \\
\hline Ilex brevicuspis & 9 & 0,01753 & 0,02013 & $-0,00169$ & 0,04343 & 0,01546 & 88,21 \\
\hline Ilex dumosa & 40 & 0,01097 & 0,00628 & $-0,00326$ & 0,09689 & 0,01675 & 152,75 \\
\hline Ilex paraguariensis & 5 & 0,01102 & 0,00870 & 0,00660 & 0,01650 & 0,00455 & 41,29 \\
\hline Jacaranda puberula & 3 & 0,00806 & 0,00654 & 0,00502 & 0,01262 & 0,00402 & 49,89 \\
\hline Lamanonia speciosa & 2 & $-0,00040$ & $-0,00040$ & $-0,00124$ & 0,00045 & 0,00120 & $-300,85$ \\
\hline Lithraea brasiliensis & 26 & 0,01644 & 0,01484 & $-0,02527$ & 0,08402 & 0,01946 & 118,33 \\
\hline Luehea divaricata & 1 & 0,02444 & - & 0,02444 & 0,02444 & - & - \\
\hline Matayba elaeagnoides & 163 & 0,02278 & 0,01483 & $-0,01417$ & 0,18015 & 0,02625 & 115,24 \\
\hline Maytenus ilicifolia & 1 & 0,00781 & - & 0,00781 & 0,00781 & - & - \\
\hline Myrcia obtecta & 11 & 0,01146 & 0,00877 & $-0,00332$ & 0,03668 & 0,01305 & 113,91 \\
\hline Nectandra grandiflora & 76 & 0,03500 & 0,03154 & $-0,00053$ & 0,10320 & 0,02402 & 68,63 \\
\hline Nectandra megapotamica & 5 & 0,06589 & 0,05246 & 0,02127 & 0,14301 & 0,04583 & 69,55 \\
\hline Ocotea corymbosa & 36 & 0,04098 & 0,02806 & 0,00000 & 0,19406 & 0,03730 & 91,02 \\
\hline Ocotea porosa & 78 & 0,05483 & 0,04663 & $-0,02680$ & 0,19156 & 0,03779 & 68,93 \\
\hline Ocotea puberula & 9 & 0,05003 & 0,03536 & 0,00902 & 0,10011 & 0,03531 & 70,58 \\
\hline Persea sp. & 1 & 0,01205 & - & 0,01205 & 0,01205 & - & - \\
\hline Prunus brasiliensis & 21 & 0,02861 & 0,02941 & $-0,00081$ & 0,09613 & 0,02280 & 79,70 \\
\hline Rapanea ferruginea & 21 & 0,03218 & 0,03281 & $-0,00094$ & 0,06291 & 0,01776 & 55,18 \\
\hline Schinus terebinthifolius & 2 & 0,00504 & 0,00504 & $-0,00520$ & 0,01528 & 0,01449 & 287,37 \\
\hline Sebastiania brasiliensis & 2 & 0,00871 & 0,00871 & 0,00605 & 0,01136 & 0,00375 & 43,13 \\
\hline Sloanea lasiocoma & 1 & 0,01853 & - & 0,01853 & 0,01853 & - & - \\
\hline Syagrus romanzoffiana & 2 & 0,00153 & 0,00153 & $-0,00052$ & 0,00357 & 0,00289 & 189,40 \\
\hline Vitex megapotamica & 1 & 0,00611 & - & 0,00611 & 0,00611 & - & - \\
\hline Zanthoxylum kleinii & 8 & 0,01639 & 0,01223 & 0,00145 & 0,03406 & 0,01122 & 68,47 \\
\hline Mirtaceae 1 & 3 & 0,01308 & 0,01159 & 0,00764 & 0,02003 & 0,00633 & 48,37 \\
\hline Não-identificadas & 2 & 0,01748 & 0,01748 & 0,00913 & 0,02583 & 0,01181 & 67,56 \\
\hline Total & 1620 & & & & & & \\
\hline
\end{tabular}

A maior quantidade de área basal morta foi verificada na parcela $30\left(7,32684 \mathrm{~m}^{2}\right)$, e em termos percentuais foi observada na parcela $1(33,26 \%)$. Essa mesma parcela apresentou a maior taxa percentual de ingresso (19,96\%). Já a parcela 30 apresentou o maior valor de área basal absoluta para os ingressos $\left(3,67755 \mathrm{~m}^{2}\right)$. A menor quantidade de matéria morta foi observada na parcela 7 , tanto em termos absolutos $\left(1,92256 \mathrm{~m}^{2}\right)$ como em termos percentuais $(8,75 \%)$. Em termos da área basal ingressa, os menores valores foram observados na parcela $10\left(1,79707 \mathrm{~m}^{2}\right.$ e $\left.7,45 \%\right)$. 
A parcela 30 (a mais desenvolvida entre as parcelas estudadas), apesar de apresentar o menor incremento líquido, foi a que se manteve mais equilibrada, o que indica que em florestas maduras o equilíbrio não significa ausência de movimento e alterações, pois foi uma das parcelas mais dinâmicas da floresta.

Tabela 13. Incremento periódico anual em diâmetro por espécie.

Table 13. Annual increment of periodic diameter per specie.

\begin{tabular}{|c|c|c|c|c|c|c|c|}
\hline Espécie & $\begin{array}{l}N^{0} \text { de } \\
\text { Árvores } \\
(9 \text { ha) }\end{array}$ & $\begin{array}{l}\text { Média } \\
\text { (cm/ano) }\end{array}$ & $\begin{array}{l}\text { Mediana } \\
\text { (cm/ano) }\end{array}$ & $\begin{array}{c}\text { Mínimo } \\
\text { (cm/ano) }\end{array}$ & $\begin{array}{l}\text { Máximo } \\
\text { (cm/ano) }\end{array}$ & $\begin{array}{c}\text { Desvio } \\
\text { Padrão } \\
\text { (cm/ano) }\end{array}$ & $\begin{array}{l}\text { C.V. } \\
(\%)\end{array}$ \\
\hline Albizia sp. & 1 & 0,48 & - & 0,48 & 0,48 & - & - \\
\hline Allophylus edulis & 5 & 0,05 & 0,07 & $-0,10$ & 0,16 & 0,10 & 192,98 \\
\hline Araucaria angustifolia & 870 & 0,32 & 0,31 & $-0,11$ & 1,14 & 0,19 & 58,30 \\
\hline Campomanesia xanthocarpa & 70 & 0,20 & 0,20 & $-0,08$ & 0,74 & 0,15 & 75,25 \\
\hline Capsicodendron dinisii & 67 & 0,14 & 0,15 & $-0,08$ & 0,42 & 0,11 & 79,29 \\
\hline Casearia inaequilatera & 3 & 0,23 & 0,19 & 0,07 & 0,44 & 0,19 & 82,40 \\
\hline Cedrela fissilis & 8 & 0,48 & 0,44 & 0,25 & 0,92 & 0,22 & 46,35 \\
\hline Cinnaтотит sellowianum & 5 & 0,43 & 0,34 & 0,27 & 0,62 & 0,16 & 36,85 \\
\hline Cinnaтотит vesiculosum & 9 & 0,31 & 0,34 & 0,05 & 0,65 & 0,19 & 59,12 \\
\hline Citronella paniculata & 1 & $-0,06$ & - & $-0,06$ & $-0,06$ & - & - \\
\hline Drimys brasiliensis & 1 & 0,13 & - & 0,13 & 0,13 & - & - \\
\hline Erythroxylum deciduum & 7 & 0,12 & 0,14 & $-0,01$ & 0,21 & 0,07 & 58,43 \\
\hline Eugenia hyemalis & 3 & 0,06 & 0,06 & 0,02 & 0,10 & 0,04 & 60,86 \\
\hline Eugenia involucrata & 16 & 0,12 & 0,09 & 0,00 & 0,33 & 0,10 & 84,38 \\
\hline Eugenia sp. & 15 & 0,06 & 0,07 & $-0,07$ & 0,15 & 0,08 & 128,71 \\
\hline Eugenia speciosa & 3 & 0,08 & 0,07 & 0,03 & 0,14 & 0,06 & 71,32 \\
\hline Eugenia uniflora & 2 & 0,12 & 0,12 & 0,10 & 0,14 & 0,03 & 25,98 \\
\hline Gochnatia polymorpha & 2 & 0,13 & 0,13 & $-0,04$ & 0,30 & 0,24 & 189,45 \\
\hline Gomidesia sellowiana & 3 & 0,27 & 0,29 & 0,15 & 0,38 & 0,12 & 42,54 \\
\hline Ilex brevicuspis & 9 & 0,13 & 0,12 & $-0,01$ & 0,33 & 0,11 & 88,20 \\
\hline Ilex dumosa & 40 & 0,10 & 0,08 & $-0,03$ & 0,59 & 0,12 & 116,33 \\
\hline Ilex paraguariensis & 5 & 0,15 & 0,12 & 0,10 & 0,22 & 0,06 & 40,05 \\
\hline Jacaranda puberula & 3 & 0,09 & 0,07 & 0,05 & 0,15 & 0,05 & 57,67 \\
\hline Lamanonia speciosa & 2 & $-0,01$ & $-0,01$ & $-0,02$ & 0,00 & 0,02 & $-235,70$ \\
\hline Lithraea brasiliensis & 26 & 0,16 & 0,16 & $-0,25$ & 0,57 & 0,17 & 101,83 \\
\hline Luehea divaricata & 1 & 0,30 & - & 0,30 & 0,30 & - & - \\
\hline Matayba elaeagnoides & 163 & 0,17 & 0,12 & $-0,10$ & 1,03 & 0,17 & 98,05 \\
\hline Maytenus ilicifolia & 1 & 0,10 & - & 0,10 & 0,10 & - & - \\
\hline Myrcia obtecta & 11 & 0,12 & 0,08 & $-0,03$ & 0,32 & 0,12 & 103,10 \\
\hline Nectandra grandiflora & 76 & 0,31 & 0,27 & 0,00 & 0,86 & 0,19 & 62,69 \\
\hline Nectandra megapotamica & 5 & 0,53 & 0,58 & 0,24 & 0,77 & 0,19 & 36,55 \\
\hline Ocotea corymbosa & 36 & 0,27 & 0,22 & 0,00 & 1,00 & 0,19 & 71,68 \\
\hline Ocotea porosa & 78 & 0,37 & 0,35 & $-0,07$ & 1,01 & 0,20 & 55,13 \\
\hline Ocotea puberula & 9 & 0,40 & 0,30 & 0,09 & 0,90 & 0,28 & 69,14 \\
\hline Persea sp. & 1 & 0,13 & - & 0,13 & 0,13 & - & - \\
\hline Prunus brasiliensis & 21 & 0,28 & 0,30 & $-0,01$ & 0,86 & 0,20 & 72,81 \\
\hline Rapanea ferruginea & 21 & 0,31 & 0,30 & $-0,01$ & 0,60 & 0,16 & 50,47 \\
\hline Schinus terebinthifolius & 2 & 0,05 & 0,05 & $-0,08$ & 0,19 & 0,19 & 338,18 \\
\hline Sebastiania brasiliensis & 2 & 0,12 & 0,12 & 0,09 & 0,15 & 0,05 & 39,60 \\
\hline Sloanea lasiocoma & 1 & 0,16 & - & 0,16 & 0,16 & - & - \\
\hline Syagrus romanzoffiana & 2 & 0,02 & 0,02 & 0,00 & 0,04 & 0,03 & 181,83 \\
\hline Vitex megapotamica & 1 & 0,08 & - & 0,08 & 0,08 & - & - \\
\hline Zanthoxylum kleinii & 8 & 0,20 & 0,16 & 0,01 & 0,38 & 0,13 & 65,02 \\
\hline Mirtaceae 1 & 3 & 0,17 & 0,16 & 0,10 & 0,24 & 0,07 & 39,76 \\
\hline Não-identificadas & 2 & 0,20 & 0,20 & 0,12 & 0,27 & 0,11 & 55,19 \\
\hline Total & 620 & & & & & & \\
\hline
\end{tabular}


Tabela 14. Incremento periódico anual em área transversal por espécie.

Table 14. Annual periodic increment in individual basal area per specie.

\begin{tabular}{|c|c|c|c|c|c|c|c|}
\hline Espécie & $\begin{array}{c}\mathbf{N}^{0} \text { de } \\
\text { Árvores } \\
\text { (9 ha) }\end{array}$ & $\begin{array}{l}\text { Média } \\
\left(\mathrm{m}^{2} / \mathbf{a n o}\right)\end{array}$ & $\begin{array}{l}\text { Mediana } \\
\left(\mathrm{m}^{2} / \mathrm{ano}\right)\end{array}$ & $\begin{array}{l}\text { Mínimo } \\
\left(\mathrm{m}^{2} / \mathbf{a n o}\right)\end{array}$ & $\begin{array}{l}\text { Máximo } \\
\left(\mathrm{m}^{2} / \mathbf{a n o}\right)\end{array}$ & $\begin{array}{c}\text { Desvio } \\
\text { Padrão } \\
\left(\mathrm{m}^{2} / \mathbf{a n o}\right)\end{array}$ & $\begin{array}{l}\text { C.V. } \\
(\%)\end{array}$ \\
\hline Albizia sp. & 1 & 0,00204 & - & 0,00204 & 0,00204 & - & - \\
\hline Allophylus edulis & 5 & 0,00018 & 0,00028 & $-0,00038$ & 0,00057 & 0,00035 & 191,33 \\
\hline Araucaria angustifolia & 870 & 0,00215 & 0,00188 & $-0,00100$ & 0,01050 & 0,00162 & 75,49 \\
\hline \multicolumn{8}{|l|}{ Campomanesia } \\
\hline xanthocarpa & 70 & 0,00093 & 0,00084 & $-0,00034$ & 0,00371 & 0,00075 & 80,96 \\
\hline Capsicodendron dinisii & 67 & 0,00073 & 0,00066 & $-0,00038$ & 0,00326 & 0,00067 & 92,00 \\
\hline Casearia inaequilatera & 3 & 0,00127 & 0,00095 & 0,00049 & 0,00238 & 0,00099 & 77,59 \\
\hline Cedrela fissilis & 8 & 0,00291 & 0,00231 & 0,00119 & 0,00702 & 0,00199 & 68,58 \\
\hline \multicolumn{8}{|l|}{ Cinnamomum } \\
\hline sellowianum & 5 & 0,00243 & 0,00229 & 0,00194 & 0,00311 & 0,00045 & 18,53 \\
\hline \multicolumn{8}{|l|}{ Cinnamomum } \\
\hline vesiculosum & 9 & 0,00177 & 0,00166 & 0,00035 & 0,00299 & 0,00093 & 52,78 \\
\hline Citronella paniculata & 1 & $-0,00030$ & - & $-0,00030$ & $-0,00030$ & - & - \\
\hline Drimys brasiliensis & 1 & 0,00068 & - & 0,00068 & 0,00068 & - & - \\
\hline Erythroxylum deciduum & 7 & 0,00047 & 0,00049 & $-0,00003$ & 0,00090 & 0,00029 & 63,19 \\
\hline Eugenia hyemalis & 3 & 0,00020 & 0,00020 & 0,00008 & 0,00031 & 0,00012 & 59,04 \\
\hline Eugenia involucrata & 16 & 0,00055 & 0,00036 & 0,00000 & 0,00140 & 0,00046 & 84,81 \\
\hline Eugenia sp. & 15 & 0,00023 & 0,00027 & $-0,00032$ & 0,00059 & 0,00031 & 133,21 \\
\hline Eugenia speciosa & 3 & 0,00044 & 0,00036 & 0,00013 & 0,00084 & 0,00036 & 82,61 \\
\hline Eugenia uniflora & 2 & 0,00046 & 0,00046 & 0,00035 & 0,00057 & 0,00016 & 33,96 \\
\hline Gochnatia polymorpha & 2 & 0,00099 & 0,00099 & $-0,00035$ & 0,00232 & 0,00189 & 191,65 \\
\hline Gomidesia sellowiana & 3 & 0,00105 & 0,00105 & 0,00057 & 0,00153 & 0,00048 & 45,85 \\
\hline Ilex brevicuspis & 9 & 0,00083 & 0,00096 & $-0,00008$ & 0,00207 & 0,00074 & 88,21 \\
\hline Ilex dumosa & 40 & 0,00052 & 0,00030 & $-0,00016$ & 0,00461 & 0,00080 & 152,75 \\
\hline Ilex paraguariensis & 5 & 0,00052 & 0,00041 & 0,00031 & 0,00079 & 0,00022 & 41,29 \\
\hline Jacaranda puberula & 3 & 0,00038 & 0,00031 & 0,00024 & 0,00060 & 0,00019 & 49,89 \\
\hline Lamanonia speciosa & 2 & $-0,00002$ & $-0,00002$ & $-0,00006$ & 0,00002 & 0,00006 & $-300,85$ \\
\hline Lithraea brasiliensis & 26 & 0,00078 & 0,00071 & $-0,00120$ & 0,00400 & 0,00093 & 118,33 \\
\hline Luehea divaricata & 1 & 0,00116 & - & 0,00116 & 0,00116 & - & - \\
\hline Matayba elaeagnoides & 163 & 0,00108 & 0,00071 & $-0,00067$ & 0,00858 & 0,00125 & 115,24 \\
\hline Maytenus ilicifolia & 1 & 0,00037 & - & 0,00037 & 0,00037 & - & - \\
\hline Myrcia obtecta & 11 & 0,00055 & 0,00042 & $-0,00016$ & 0,00175 & 0,00062 & 113,91 \\
\hline $\begin{array}{l}\text { Nectandra grandiflora } \\
\text { Nectandra }\end{array}$ & 76 & 0,00167 & 0,00150 & $-0,00003$ & 0,00491 & 0,00114 & 68,63 \\
\hline megapotamica & 5 & 0,00314 & 0,00250 & 0,00101 & 0,00681 & 0,00218 & 69,55 \\
\hline Ocotea corymbosa & 36 & 0,00195 & 0,00134 & 0,00000 & 0,00924 & 0,00178 & 91,02 \\
\hline Ocotea porosa & 78 & 0,00261 & 0,00222 & $-0,00128$ & 0,00912 & 0,00180 & 68,93 \\
\hline Ocotea puberula & 9 & 0,00238 & 0,00168 & 0,00043 & 0,00477 & 0,00168 & 70,58 \\
\hline Persea sp. & 1 & 0,00057 & - & 0,00057 & 0,00057 & - & - \\
\hline Prunus brasiliensis & 21 & 0,00136 & 0,00140 & $-0,00004$ & 0,00458 & 0,00109 & 79,70 \\
\hline Rapanea ferruginea & 21 & 0,00153 & 0,00156 & $-0,00004$ & 0,00300 & 0,00085 & 55,18 \\
\hline Schinus terebinthifolius & 2 & 0,00024 & 0,00024 & $-0,00025$ & 0,00073 & 0,00069 & 287,37 \\
\hline Sebastiania brasiliensis & 2 & 0,00041 & 0,00041 & 0,00029 & 0,00054 & 0,00018 & 43,13 \\
\hline Sloanea lasiocoma & 1 & 0,00088 & - & 0,00088 & 0,00088 & - & - \\
\hline Syagrus romanzoffiana & 2 & 0,00007 & 0,00007 & $-0,00002$ & 0,00017 & 0,00014 & 189,40 \\
\hline Vitex megapotamica & 1 & 0,00029 & - & 0,00029 & 0,00029 & - & - \\
\hline Zanthoxylum kleinii & 8 & 0,00078 & 0,00058 & 0,00007 & 0,00162 & 0,00053 & 68,47 \\
\hline Mirtaceae 1 & 3 & 0,00062 & 0,00055 & 0,00036 & 0,00095 & 0,00030 & 48,37 \\
\hline Não-identificadas & 2 & 0,00083 & 0,00083 & 0,00043 & 0,00123 & 0,00056 & 67,56 \\
\hline Total & 1620 & & & & & & \\
\hline
\end{tabular}

A floresta (9 ha) tinha, em 1979, 2133 indivíduos arbóreos. Ao final do período estudado restavam 2202 indivíduos arbóreos, constatando-se 513 mortos e o ingresso de 591. Se essas informações forem analisadas em conjunto com a Tabela 15, verifica-se o quanto enganosa pode ser a análise da 
dinâmica baseada no número de árvores. No caso da floresta "inteira", conclui-se, baseado no número de árvores, que houve mais ingresso do que mortalidade. Por outro lado, a análise da Tabela 15 mostra que, tanto em termos absolutos como em termos percentuais, a quantidade de matéria morta foi maior que a quantidade de matéria que ingressou na floresta. Esse fato é motivado pelas pequenas dimensões das árvores ingressas quando comparadas às árvores mortas.

Tabela 15. Dinâmica em termos da área basal para as parcelas e para a floresta ( 9 ha) no período de 1979-2000.

Table 15. Basal area dynamic for plots and forest (9 ha) in 1979-2000 period.

\begin{tabular}{ccccccccc}
\hline \multirow{2}{*}{ Parcela } & \multicolumn{2}{c}{$\mathbf{G}_{\mathbf{V}}$} & \multicolumn{2}{c}{$\mathbf{G}_{\mathbf{m}}$} & \multicolumn{2}{c}{$\mathbf{G}_{\mathbf{i n}}$} & \multicolumn{2}{c}{ IG } \\
\cline { 2 - 8 } & $\mathbf{( \mathbf { m } ^ { 2 } / \mathbf { h a } )}$ & $\mathbf{( \% )}$ & $\mathbf{( \mathbf { m } ^ { \mathbf { 2 } } / \mathbf { h a } )}$ & $\mathbf{( \% )}$ & $\mathbf{( \mathbf { m } ^ { \mathbf { 2 } } / \mathbf { h a } )}$ & $\mathbf{( \% )}$ & $\left.\mathbf{( m}^{\mathbf{2}} / \mathbf{h a}\right)$ & $\mathbf{( \% )}$ \\
\hline 1 & 4,87654 & 29,00 & 5,59260 & 33,26 & 3,35698 & 19,96 & 2,64091 & 15,70 \\
6 & 6,52237 & 30,71 & 4,12746 & 19,43 & 3,03514 & 14,29 & 5,43005 & 25,57 \\
7 & 7,55937 & 34,42 & 1,92256 & 8,75 & 3,85095 & 17,53 & 9,48777 & 43,20 \\
10 & 6,12920 & 25,42 & 2,97002 & 12,32 & 1,79707 & 7,45 & 4,95624 & 20,56 \\
17 & 7,36330 & 30,79 & 3,44937 & 14,43 & 2,15256 & 9,00 & 6,06649 & 25,37 \\
18 & 6,71782 & 26,51 & 4,88172 & 19,26 & 2,59945 & 10,26 & 4,43555 & 17,50 \\
21 & 5,20117 & 25,34 & 5,37599 & 26,19 & 3,61760 & 17,62 & 3,44278 & 16,77 \\
22 & 7,00829 & 28,01 & 5,57358 & 22,28 & 3,28522 & 13,13 & 4,71993 & 18,86 \\
30 & 7,68505 & 23,44 & 7,23684 & 22,07 & 3,67755 & 11,22 & 4,12576 & 12,58 \\
\hline Total & $\mathbf{5 9 , 0 6 3 1 0}$ & $\mathbf{2 7 , 9 0}$ & $\mathbf{4 1 , 1 3 0 1 4}$ & $\mathbf{1 9 , 4 3}$ & $\mathbf{2 7 , 3 7 2 5 3}$ & $\mathbf{1 2 , 9 3}$ & $\mathbf{4 5 , 3 0 5 4 9}$ & $\mathbf{2 1 , 4 0}$ \\
\hline
\end{tabular}

$G_{V}=$ somatório do incremento em área basal das árvores vivas; $G_{m}=$ somatório da área basal das árvores mortas;

$G_{i n}=$ somatório da área basal dos ingressos; $I G=$ incremento líquido em área basal

\section{CONCLUSÕES}

Com base nas informações obtidas sobre incremento em diâmetro e em área basal em uma Floresta Ombrófila Mista num período compreendido entre 1979 e 2000, é possível concluir que:

- A distribuição dos incrementos diamétricos da floresta é bimodal, porém em área transversal é unimodal; entretanto, ambos apresentaram assimetria à direita (positiva).

- Os indivíduos arbóreos da floresta (9 ha) cresceram em 21 anos, em termos de mediana, $5,30 \mathrm{~cm}(0,25 \mathrm{~cm} / \mathrm{ano})$ em diâmetro e $0,0288 \mathrm{~m}^{2}\left(0,0014 \mathrm{~m}^{2} / \mathrm{ha}\right)$ em área transversal.

- Os incrementos variaram também em função das espécies e das parcelas. A parcela 1 foi a que apresentou os maiores incrementos; a parcela 10, os menores.

- Nectandra megapotamica foi a espécie que apresentou os maiores incrementos (mediana de $12,2 \mathrm{~cm}$ no período ou $0,58 \mathrm{~cm} / \mathrm{ano}$ ), seguida de Cedrela fissilis, com mediana de 9,20 cm ou $0,44 \mathrm{~cm} /$ ano. Por outro lado, Eugenia sp. e Allophylus edulis foram as espécies com os menores incrementos (mediana de $1,90 \mathrm{~cm}$ ou $0,09 \mathrm{~cm} / \mathrm{ano}$ ).

- As espécies com as maiores taxas de incremento também apresentaram menor variabilidade no padrão de crescimento - menor coeficiente de variação.

- De maneira geral, as lauráceas foram as espécies que mais cresceram, e as mirtáceas as que menos cresceram.

- Os incrementos da floresta variaram em função das classes de diâmetro, da vitalidade, posição sociológica e qualidade do fuste, sendo maiores para: classes de diâmetro intermediárias (40 a $80 \mathrm{~cm}$ ), classe de melhor vitalidade, estrato superior e classe de melhor qualidade de fuste.

- A floresta amadureceu no período estudado, pois teve um crescimento líquido em área basal de $45,3055 \mathrm{~m}^{2}\left(5,0339 \mathrm{~m}^{2} / \mathrm{ha}\right.$ ou $\left.0,2397 \mathrm{~m}^{2} / \mathrm{ha} / \mathrm{ano}\right)$, mostrando que havia espaço de crescimento, ou seja, a floresta não estava completamente estocada em 1979. 


\section{REFERÊNCIAS}

ALDER, D.; SYNNOTT, T. J. Permanent sample plot techniques for mixed tropical forest. Tropical Forestry Papers, Oxford, n.25, 124p. 1992.

DILLEWIJN, F. Inventário do Pinheiro no Paraná. Curitiba: Cerena, 1966. 104p.

DURIGAN, M. E. Florística, dinâmica e análise protéica de uma Floresta Ombrófila Mista em São João do Triunfo - PR. Curitiba, 1999. 125f. Dissertação (Mestrado em Engenharia Florestal) - Setor de Ciências Agrárias, Universidade Federal do Paraná.

EDUARDO, R. P. A madeira em Santa Catarina. Curitiba, 1974. 171 f. Dissertação (Mestrado em História do Brasil) - Setor de Ciências Humanas, Letras e Artes, Universidade Federal do Paraná.

ESCOLA DE FLORESTAS. Inventário Florestal de Reconhecimento das Florestas de Araucária das Formações Sedimentares do Paleozóico nos Estados do Paraná e Santa Catarina. Curitiba: UFPR, 1967.

FUNDAÇÃO DE PESQUISAS FLORESTAIS DO PARANÁ. Inventário Florestal do Pinheiro no Sul do Brasil. Curitiba: 1978.327 p.

GAUTO, O. A. Análise da dinâmica e impactos da exploração sobre o estoque remanescente (por espécies e por grupos de espécies similares) de uma Floresta Estacional Semidecidual em Missiones, Argentina. Curitiba, 1997. 133 f. Dissertação (Mestrado em Ciências Florestais) - Setor de Ciências Agrárias, Universidade Federal do Paraná.

GOLDSMITH, F. B.; HARRISON, C. M. Description and analysis of vegetation. In: CHAPMAN, S.B. (Ed.) Methods in plant ecology. London: Blackwell Scientific, 1976. p.85-155.

GOMIDE, G. L. A. Estrutura e dinâmica de crescimento de florestas tropicais primária e secundária no Estado do Amapá. Curitiba, 1997. 172f. Dissertação (Mestrado em Ciências Florestais) Setor de Ciências Agrárias, Universidade Federal do Paraná.

HEINSDIJK, D. Volumes do Pinheiro., Rio de Janeiro SIF-SP, 1959.

HUSCH, B.; MILLER, C. I.; BEERS, T. W. Forest mensuration. 3ed. New York: John Wiley \& Sons, 1982. 402p

IBGE. Manual técnico da vegetação brasileira.. Rio de Janeiro: 1992. 92p. n.1. Série Manuais Técnicos em Geociências

KOHYAMA, T ; HARA, T. Frequency distribution of tree growth rate in natural forest stands. Annals of Botany,London, GB, v.64, p.47-57, 1989.

LONGHI, S. J. A estrutura de uma floresta natural de Araucaria angustifolia (Bert.) O. Ktze, no sul do Brasil. Curitiba, 1980. 198 f. Dissertação (Mestrado em Engenharia Florestal) - Setor de Ciências Agrárias, Universidade Federal do Paraná.

MAACK, R. Urwald und Savanneim Landschaftsbild des States Paraná. Zetschr.d. Ges. f. Erdk. zu Berlin, n. 3/4. 1931.

MARTINS, F. R. A estrutura de uma floresta mesófila. Campinas: Editora de UNICAMP, 1991. 246p.

OLIVER, C. D.; LARSON, B. C. Forest stand dynamics. New York: McGraw-Hill, 1996. 467p.

PÉLLICO-NETTO, S. Recursos florestais do Sul do Brasil. Floresta, Curitiba, v. 3, n.2, p.68-74, 1971.

PIZATTO, W. Avaliação biométrica da estrutura e da dinâmica de uma Floresta Ombrófila Mista em São João do Triunfo - PR: 1995 a 1998. Curitiba, 1999. 172 f. Dissertação (Mestrado em Engenharia Florestal) - Setor de Ciências Agrárias, Universidade Federal do Paraná.

PRODAN, M.; PETERS, R.; COX, F.; REAL, P. Mensura Forestal. San José, C.R.: Deutsche Gesellschaft für Technische Zusammenarbeit (GTZ) GmbH, 1997. 561p. 
PULZ, F. A. Estudo da dinâmica e a modelagem da estrutura diamétrica de uma floresta semidecídua montana na região de Lavras, MG. Lavras, 1998. 156p. Dissertação (Mestrado em Engenharia Florestal) - Universidade Federal de Lavras.

RODRÍGUEZ TELLO, J. C. Eficiência e custos de diferentes formas e tamanhos de unidades de amostra em uma floresta nativa de Araucaria angustifolia (Bert.) o Ktze no sul do Brasil. Curitiba, 1980. 126f. Dissertação (Mestrado em Engenharia Florestal) - Setor de Ciências Agrárias, Universidade Federal do Paraná.

SCHAAF, L. B. Florística, estrutura e dinâmica no período 1979-2000 de uma Floresta Ombrófila Mista localizada no Sul do Paraná. Curitiba, 2001. 131f. Dissertação (Mestrado em Engenharia Florestal) - Setor de Ciências Agrárias, Universidade Federal do Paraná.

VANCLAY, J. K. Modeling Forest growth and yield. Copenhagen: Cab International, 1994. 312p.

WEST, P. W. Use of diameter and basal area increment in tree growth studies. Canadian Journal of Forest Research, Otawa, CA, v.10, p.71-77, 1980. 